\title{
Nanoformulations of Ursolic Acid: A Modern Natural Anticancer Molecule
}

\author{
Longyun Wang ${ }^{1 \dagger}$, Qianqian Yin ${ }^{1 \dagger}$, Cun Liu $^{2}$, Ying Tang ${ }^{3}$, Changgang Sun ${ }^{4,5 *}$ and \\ Jing Zhuang ${ }^{4 *}$
}

${ }^{1}$ College of Traditional Chinese Medicine, Shandong University of Traditional Chinese Medicine, Jinan, China, ${ }^{2}$ College of First Clinical Medicine, Shandong University of Traditional Chinese Medicine, Jinan, China, ${ }^{3}$ Department of Hematology, Affiliated Hospital of Weifang Medical University, Weifang, China, ${ }^{4}$ Department of Oncology, Weifang Traditional Chinese Hospital, Weifang, China, ${ }^{5}$ Qingdao Academy of Chinese Medical Sciences, Shandong University of Traditional Chinese Medicine, Qingdao, China

Background: Ursolic acid (UA) is a natural pentacyclic triterpene derived from fruit, herb, and other plants. UA can act on molecular targets of various signaling pathways, inhibit the growth of cancer cells, promote cycle stagnation, and induce apoptosis, thereby exerting anticancer activity. However, its poor water-solubility, low intestinal mucosal absorption, and low bioavailability restrict its clinical application. In order to overcome these deficiencies, nanotechnology, has been applied to the pharmacological study of UA.

OPEN ACCESS

Edited by:

Carmela Fimognari,

University of Bologna, Italy

Reviewed by:

Dharmendra Kumar Yadav, Gachon University, South Korea

Hardeep Singh Tuli,

Maharishi Markandeshwar University,

Mullana, India

*Correspondence:

Changgang Sun

scgdoctor@126.com

Jing Zhuang

zhuangjing1226@163.com

${ }^{\dagger}$ These authors have contributed equally to this work

Specialty section:

This article was submitted to Pharmacology of Anti-Cancer Drugs,

a section of the journal

Frontiers in Pharmacology

Received: 06 May 2021

Accepted: 22 June 2021

Published: 05 July 2021

Citation:

Wang L, Yin Q, Liu C, Tang Y, Sun C and Zhuang $J$ (2021) Nanoformulations of Ursolic Acid: A Modern Natural Anticancer Molecule.

Front. Pharmacol. 12:706121.

doi: 10.3389/fphar.2021.706121
Objective: In this review, we focused on the absorption, distribution, and elimination pharmacokinetics of UA in vivo, as well as on the research progress in various UA nanoformulations, in the hope of providing reference information for the research on the anticancer activity of UA.

Methods: Relevant research articles on Pubmed and Web of Science in recent years were searched selectively by using the keywords and subheadings, and were summarized systematically.

Key finding: The improvement of the antitumor ability of the UA nanoformulations is mainly due to the improvement of the bioavailability and the enhancement of the targeting ability of the UA molecules. UA nanoformulations can even be combined with computational imaging technology for monitoring or diagnosis.

Conclusion: Currently, a variety of UA nanoformulations, such as micelles, liposomes, and nanoparticles, which can increase the solubility and bioactivity of UA, while promoting the accumulation of UA in tumor tissues, have been prepared. Although the research of UA in the nanofield has made great progress, there is still a long way to go before the clinical application of UA nanoformulations.

Keywords: ursolic acid, natural molecule, cancer, pharmacokinetics, nanoformulations

\section{INTRODUCTION}

\section{A Close Connection Between UA and Cancer}

Cancer is a complex disease caused by the abnormal proliferation of cells under the action of multiple factors ( $\mathrm{Yu}$ et al., 2018). Over the years, natural products, with significant anticancer potential and the ability to act as bioenhancers to increase the activity of existing anticancer drugs, have been an unrivaled medicine source (Choudhari et al., 2019; Dwivedi et al., 2019). Data show that more than 
$70 \%$ of FDA-approved cancer drugs come from natural products or natural product derivatives (Katz and Baltz, 2016; Cargnin and Gnoatto, 2017). Natural compounds can inhibit the formation and development of cancer through specific interactions with a variety of cell signaling pathways, thereby confirming the intriguing anticancer effectiveness of natural products (Calcabrini et al., 2017). Studies have shown that the natural molecule ursolic acid (UA) can regulate the proliferation, metastasis, angiogenesis, and apoptosis of tumor cells by acting on a variety of cytokines (Figure 1), and has a significant therapeutic effect on breast, lung, colorectal, liver, and prostate cancer as well as on other tumors (Mu et al., 2018; Zhang et al., 2020a; Gou et al., 2020b; Chen et al., 2020; Shao et al., 2020). The detailed roles of UA in the treatment of cancer are shown in Table 1.

\section{The Source and Characteristics of UA Molecule}

Ursolic acid (3 $\beta$-hydroxy-urs-12-en-28-oic-acid, PubChem CID: 64945, CAS:77-52-1, Figure 2), with the molecular formula $\mathrm{C}_{30} \mathrm{H}_{48} \mathrm{O}_{3}$ and a molecular weight of $456.7 \mathrm{~g} / \mathrm{mol}$, is a natural arbutin pentacyclic triterpenoid, which is widely found in fruits, medicinal materials, and other plants (Son and Lee, 2020). Pentacyclic triterpenes (PTs) are natural secondary metabolites of plants and many other organisms. First discovered in the 1920s from apple epidermis wax, UA has been isolated from many other plant organs in recent years. Examples include pears, olives, plums, cranberries, Fructus Chaenomelis Lagenariae, Fructus Mume, Fructus Gardeniae, Fructus Ligustri Lucidi, and Hedyotis diffusa Willd, among others (Ikeda et al., 2008; Sun Q. et al., 2020). This compound has a wide range of biological and pharmacological properties, in addition to attractive functional cytotoxic properties, including anti-inflammatory, antioxidant, anti-allergy, antiviral, antibacterial, liver protection, sedative, anti-ulcer, lipid-lowering, and anti-diabetic effects (Wan et al., 2019). It is worth noting that although UA is a promising bioactive molecule, there are still many obstacles that need to be overcome before it can truly reach its potential.

The pentacyclic terpene UA structure (C-30 isoprenoid, alcoholic $\mathrm{NaOH}$, and glacial acetic acid) has good solubility; however, its solubility in water is low, leading to poor oral drug absorption in the body, short half-life, and low bioavailability. These disadvantages limit its wide application in the pharmaceutical field, and it has been classified as class IV in the biological drug classification system (BCS) (Yu et al., 2020). UA has been studied extensively in efforts to overcome its pharmacological limitations and enhance its therapeutic effects; some research methods have included structural modification or nanomaterial preparation. Kalani et al. verified the significant time-dose dependent anti-cancer activity of UA derivatives through quantitative structure-activity relationship (Kalani et al., 2012; Kalani et al., 2014). Khwaza et al. (2020) summarized the anticancer activity of UA derivatives after structural modification, showing that the molecular structure modification of UA mainly involves three sites: the C28 carboxyl group, the $\mathrm{C} 3$ hydroxyl group, and the $\mathrm{C} 12-\mathrm{C} 13$ double bond. However, it is noteworthy that not all new UA derivatives exhibit enhanced anticancer activity. On the contrary, some exhibit decreased anticancer activity, which may be due to the different modification sites or pathways of UA (Manayi et al., 2018). UA nanoformulations change the pharmacokinetic properties of UA by reducing the particle size, changing the surface performance, and improving stability, thus achieving the effect of improving its anticancer activity and reducing adverse reactions.

\section{The Basic Strategy of Nanoformulations Applied to Tumor Tissues}

Nanoformulations have broader prospects in the field of anticancer research, with the successful marketing of doxorubicin long-cycle liposomes and paclitaxel albumin nanoparticles. The enhanced permeability and retention effect (EPR effect, Figure 3) is the most basic strategy of nanopreparation applied to tumor tissues (Nakamura et al., 2016). The vascular networks of tumor tissues differ greatly from those of normal tissues. The rapid growth of cancer cells incurs a high oxygen demand, leading to angiogenesis in tumor tissues. The new blood vessels are characterized by irregularity and absence of a basement membrane, which leads to the high permeability of the tumor blood vessel network to some extent. In addition, damage to the lymphatic system in tumor tissues inhibits the re-entry of components into blood circulation, thus allowing them to remain in tumor tissues. The EPR effect promotes the high accumulation of nanoformulations in tumor tissues (compared to normal tissues), reduces the side effects of chemotherapy drugs, and provides a good opportunity for the treatment of cancer with nanoformulations (Li Q. et al., 2019; Kalyane et al., 2019).

To date, a variety of UA nanoformulations, such as liposomes, nanoparticles, and micelles, which have effectively improved the pharmacokinetic properties of UA and can act better on tumor tissues through the EPR effect, have been developed successively. In this paper, we summarized the current pharmacokinetic studies on UA, on topics such as the absorption, distribution, and elimination of UA as well as on the developed UA nanoformulations, in an effort to provide references and information for the drug design and rational application of UA.

\section{REVIEW OF UA PHARMACOKINETICS}

\section{Absorption}

As UA is mainly absorbed by the intestinal tract through passive diffusion, its absorption rate is very fast. The concentration of UA reached a peak of $1.10 \pm 0.31 \mu \mathrm{g} / \mathrm{mL}$ approximately $0.5 \mathrm{~h}$ after the oral administration of $10 \mathrm{mg} / \mathrm{kg}$ UA (extracted from Calendula officinalis Sieb. et Zucc) (Chen et al., 2011). One study showed that the uptake of UA by Caco2 cell monolayers showed a linear increase, with no obvious saturation trend in the concentration range of $10-40 \mu \mathrm{g} / \mathrm{mL}$ (Jinhua, 2019). Another study reported that the uptake of UA (the suspension dissolved in DEMSO) by Caco-2 cell monolayers was significantly directional. It was also 


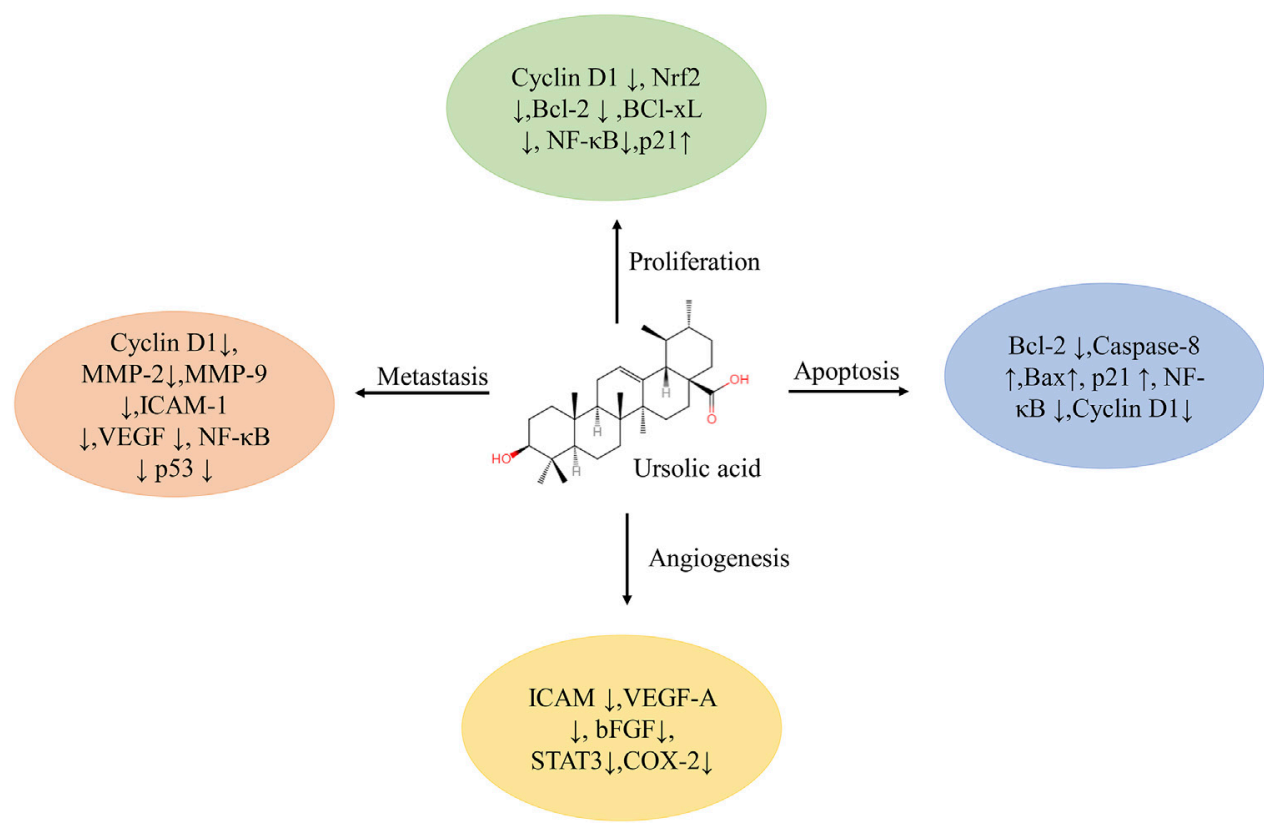

FIGURE 1 | Multiple molecular targets modulated by ursolic acid. Abbreviations: Bcl-2, B-cell lymphoma-2; Bcl-xL, B-cell Lymphoma/Leukemia-xL; bFGF, basic fibroblast growth factor; COX, cyclooxygenase; ICAM, intercellular adhesion molecule; MMP, matrix metalloprotease; NF-kB, nuclear factor kappa-B; Nrf, nuclear factor E2-related factor; STAT, signal transducers and activators of transcription; VEGF, vascular endothelial growth factor.

observed that the absorption of UA is influenced by temperature and $\mathrm{pH}$ values. The absorption of $\mathrm{UA}$ is more active at $4^{\circ} \mathrm{C}$ (when the temperature of the culture system was 4,25 , and $37^{\circ} \mathrm{C}$ ) and the absorption significantly decreased under alkaline conditions (when the $\mathrm{pH}$ value of the culture system was 5.5-8.0) (Hua et al., 2012). The absorption of UA is mainly mediated by P-glycoprotein (P-gp) transporters, and studies have shown that pregnane $\mathrm{X}$ receptor (PXR) affects $\mathrm{P}$-gp abundance. After PXR was silenced in Caco2-siRNA-PXR cells, the apparent permeability ratio values were $1.85 \pm 0.36,1.24 \pm 0.11$, and $1.19 \pm 0.04$ when UA concentrations were 10,20 , and $50 \mu \mathrm{M}$, respectively. In Caco2 cells without PXR silencing, the apparent permeability ratio values increased to $2.19 \pm 0.44,1.40 \pm 0.17$, and $1.25 \pm 0.07$, respectively (Jinhua et al., 2020). UA contains hydroxyl (C3) molecules, which are likely to be acidified by glucosaldehydes or sulfates in intestinal cells. After a $\beta$-glucuronidase/sulfatase treatment, the apparent permeability coefficient (PAPP) of UA in Caco2 cell monolayers decreases from $2.7 \times 10^{-6}$ to $2.3 \times 10^{-6} \mathrm{~cm} / \mathrm{s}$. Therefore, to some extent, UA acidification or sulfurization results in low UA bioavailability (Qiang et al., 2011).

\section{Distribution}

The UA-related tissue distribution has been studied. In animal models, UA is mainly distributed in the liver, heart, spleen, kidneys, and other organs. After $19.69 \mathrm{mg} / \mathrm{kg}$ of UA (extracted from Hedyotis diffusa Willd) was administered to healthy Sprague-Dawley rats, organ samples were collected. The tissue concentrations of UA were measured in the liver, kidneys, spleen, heart, and lungs. In addition, the distribution of UA in C57BL/6 mice was analyzed, and the results also showed that the concentrations of UA in the liver, kidneys, and heart increased gradually with the observation time (Yin et al., 2012; Chen X. et al., 2018). These results suggest that UA distribution may be related to blood flow and the perfusion rate. Why is the concentration of UA in the liver so high? Organic anionic transport polypeptides (OATPs) are transmembrane proteins involved in the uptake of various endogenous and exogenous compounds and in the pharmacokinetics and drug-drug interactions of clinically relevant compounds (Patik et al., 2015). Moreover, UA was found to be the substrate of OATP1B1, and OATP1B1 presumably mediates the transport of UA to liver cells, which further explains the phenomenon of high UA concentrations in the liver. Of course, OATP1B3 may also mediate the transport of UA to hepatocytes (Roth et al., 2011).

\section{Elimination (Metabolism and Excretion)}

Liver is an important metabolic organ, in which UA mainly distributed among previous studies. PXR is highly expressed in hepatocytes and plays a key role in regulating some metabolic enzymes in downstream regions. Cytochrome P450 (CYP) enzymes are among the most important metabolic enzymes in the liver. Thus, in the experiments on $\mathrm{Caco} 2$ cells and Caco2PXR-RXRa cells, the Km values of UA are $81.99 \pm 44.32$ and $60.05 \pm 29.62 \mathrm{~g} / \mathrm{mL}$, respectively, and the $V_{\max }$ values are $3.77 \pm$ 0.86 and $3.41 \pm 0.96 \mu \mathrm{g} \mathrm{ml}^{-1} \mathrm{~min}^{-1}$, respectively (Jinhua et al., 2020). In addition, it has also been reported that the conversion rate of UA in human liver microsomes containing the prototype coenzyme II (NADPH) is approximately $40 \%$ after a 20 -min 
TABLE 1 | The detailed role of UA and cancer.

\begin{tabular}{|c|c|c|c|c|c|}
\hline $\begin{array}{l}\text { Types of } \\
\text { cancer }\end{array}$ & Cell line used & $\begin{array}{l}\text { Study } \\
\text { type }\end{array}$ & Therapeutic effect & Mechanism of action & References \\
\hline \multirow[t]{14}{*}{$\begin{array}{l}\text { Breast } \\
\text { Cancer }\end{array}$} & MCF-7 & In vitro & Inhibit cell growth & $\begin{array}{l}\text { Down-regulate the phosphorylation of PLK1 } \\
\text { Inhibit RAF/ERK pathway and IKK/NF-kB } \\
\text { pathway }\end{array}$ & Guo et al. (2020a) \\
\hline & \multirow[t]{2}{*}{ MCF-7 } & \multirow[t]{2}{*}{ In vitro } & $\begin{array}{l}\text { Inhibit invasiveness and } \\
\text { migration }\end{array}$ & Inhibit PMA-induced MMP-9 expression & \multirow[t]{2}{*}{ Chung et al. (2017) } \\
\hline & & & Induce apoptosis & $\begin{array}{l}\text { Down-regulate the phosphorylation of } \mathrm{p}-\mathrm{ERK} \text { and } \\
\mathrm{p} \text {-p38 } \\
\text { activate caspase- } 8 \text {, caspase- } 7 \text { and poly ADP- } \\
\text { ribose polymerase; up-regulate the expression of } \\
\text { Bax and down-regulate the expression of Bcl-2 }\end{array}$ & \\
\hline & MDA-MB-231 & In vitro & Inhibit cell proliferation & $\begin{array}{l}\text { Down-regulate Nrf2 via Keap1/Nrf2 pathway and } \\
\text { EGFR/Nrf2 pathway }\end{array}$ & Zhang et al. (2020a) \\
\hline & MCF-7, MDA-MB-231 & In vitro & $\begin{array}{l}\text { Control cell proliferation; } \\
\text { induce apoptosis }\end{array}$ & Inhibit the activity of CDK6 & Yousuf et al. (2020) \\
\hline & MCF-7 & In vitro & Inhibit cell survival & - & $\begin{array}{l}\text { Lam et al. (2019), Ngo et al. } \\
\text { (2019) }\end{array}$ \\
\hline & 184-B5,184-B5/HER & In vitro & Induce apoptosis & $\begin{array}{l}\text { Down-regulate the expression of } \mathrm{Bcl}-2 \text {; up- } \\
\text { regulate the expression of } \mathrm{Bax}\end{array}$ & Telang, (2018) \\
\hline & $\begin{array}{l}\text { T47D, MCF-7, MDA- } \\
\text { MB-231 }\end{array}$ & In vitro & $\begin{array}{l}\text { Inhibit cell proliferation } \\
\text { Induce autophagy and } \\
\text { apoptosis }\end{array}$ & $\begin{array}{l}\text { Down-regulate the expressions of Bcl-2, cyclin- } \\
\text { D1 and NF-kB } \\
\text { Up-REGULATE GSK through decreasing PI3K } \\
\text { AKT pathway }\end{array}$ & Luo et al. (2017) \\
\hline & $\begin{array}{l}\text { SUM149PT, HCC 1937, } \\
\text { MDA-MB-231 }\end{array}$ & In vitro & $\begin{array}{l}\text { Induce cell cycle arrest; } \\
\text { induce apoptosis }\end{array}$ & - & $\begin{array}{l}\text { Gu et al. (2017); Li W. et al. } \\
\text { (2018) }\end{array}$ \\
\hline & MDA-MB-231 & In vitro & $\begin{array}{l}\text { Induce cell cycle arrest; } \\
\text { induce apoptosis }\end{array}$ & $\begin{array}{l}\text { Down-regulate PCNA, CDK4, and Cyclin-D1; up- } \\
\text { regulate p } 21^{\text {Waf1/Cip } 1} \\
\text { Induce the activation of caspase- } 9 \text { and caspase-3 } \\
\text { by mitochondrial death pathway }\end{array}$ & Wen et al. (2017) \\
\hline & HCC1806 & In vitro & $\begin{array}{l}\text { Induce cell cycle arrest; } \\
\text { induce apoptosis }\end{array}$ & $\begin{array}{l}\text { Down-regulate the activation of STAT3 } \\
\text { Up-regulate the expressions of p21 and p27 }\end{array}$ & Li W. et al. (2017) \\
\hline & $\begin{array}{l}\text { MCF-7, MDA-MB-231, SK- } \\
\text { BR-3 }\end{array}$ & In vitro & Inhibit cell proliferation & $\begin{array}{l}\text { Up-regulate the levels of p21, superoxide and } \\
\text { protein carbonylation } \\
\text { Down-regulate the levels of NOP2, p120 and } \\
\text { WDR12 }\end{array}$ & Lewinska et al. (2017b) \\
\hline & $\begin{array}{l}\text { MCF-7, MDA-MB-231, SK- } \\
\text { BR-3 }\end{array}$ & In vitro & $\begin{array}{l}\text { Induce autophagy and } \\
\text { apoptosis }\end{array}$ & $\begin{array}{l}\text { Up-regulate the levels of p21 } \\
\text { Down-regulate the levels of HK2, PKM2, ATP and } \\
\text { lactate via AKT signaling pathway }\end{array}$ & Lewinska et al. (2017a) \\
\hline & $\begin{array}{l}\text { Mice xenografted with } \\
\text { MMTV-Wnt-1 mammary } \\
\text { tumor cells }\end{array}$ & In vivo & $\begin{array}{l}\text { Reduce tumor volume; } \\
\text { induce apoptosis and arrest } \\
\text { cell cycle }\end{array}$ & Modulate Akt/mTOR signaling pathways & $\begin{array}{l}\text { (De Angel et al., 2010; } \\
\text { Wang M. et al. (2020) }\end{array}$ \\
\hline \multirow[t]{8}{*}{ Lung Cancer } & $\mathrm{A} 549, \mathrm{H} 460$ & In vitro & $\begin{array}{l}\text { Induce cell cycle arrest } \\
\text { Induce apoptosis }\end{array}$ & $\begin{array}{l}\text { Up-regulate the levels of } \mathrm{CHOP} \text {, Bax and } \\
\text { caspase- } 8 \text { through ER stress pathway }\end{array}$ & Gou et al. (2020a) \\
\hline & A549 & In vitro & Inhibit autophagy & INHIBIT the mTOR signaling pathway & Wang M. et al. (2020) \\
\hline & H549 & In vitro & Induce apoptosis & Activate AKT/mTOR pathway & $\begin{array}{l}\text { Castrejón-Jiménez et al. } \\
\text { (2019) }\end{array}$ \\
\hline & $\mathrm{H} 292$ & In vitro & $\begin{array}{l}\text { Inhibit cell survival } \\
\text { Induce apoptosis }\end{array}$ & $\begin{array}{l}\text { Up-regulate the expression levels of AIF and Endo } \\
\text { G through a mitochondria-dependent pathway }\end{array}$ & Chen et al. (2019) \\
\hline & A549 & In vitro & $\begin{array}{l}\text { Induce cell cycle arrest } \\
\text { Induce apoptosis }\end{array}$ & Block the NF-кB signaling pathway & Jiang et al. (2018) \\
\hline & H1975 & In vitro & $\begin{array}{l}\text { Inhibit invasiveness and } \\
\text { metastasis }\end{array}$ & $\begin{array}{l}\text { Decrease the level of E-cadherin and elevate the } \\
\text { level of N-cadherin through TGF- } \beta 1 \text { signaling } \\
\text { pathway } \\
\text { Decrease the levels of MMP-2 and MMP - } 9\end{array}$ & Ruan et al. (2019) \\
\hline & $\mathrm{H} 460$ & In vitro & $\begin{array}{l}\text { Inhibit cell survival } \\
\text { Induce apoptosis }\end{array}$ & $\begin{array}{l}\text { Activate the levels of caspase- } 8 \text { and caspase- } 7 \\
\text { and decrease the level of Bcl-2 } \\
\text { Increase the levels of Beclin- } 1 \text { and LC3A/B-II and } \\
\text { decrease the level of mTOR and p62 }\end{array}$ & Mendes et al. (2016) \\
\hline & $\begin{array}{l}\mathrm{H} 1299, \mathrm{~A} 549, \mathrm{H} 1650 \\
\mathrm{H} 358, \mathrm{H} 1975\end{array}$ & In vitro & $\begin{array}{l}\text { Inhibit cell growth } \\
\text { Induced apoptosis }\end{array}$ & $\begin{array}{l}\text { Induce phosphorylation of SAPK/JNK and } \\
\text { suppress the protein expression of DNMT1 and } \\
\text { EZH2 }\end{array}$ & Wu et al. (2015) \\
\hline \multirow[t]{2}{*}{$\begin{array}{l}\text { Colorecta-I } \\
\text { Cancer }\end{array}$} & $\mathrm{RKO}$ & In vitro & $\begin{array}{l}\text { Inhibit cell proliferation; } \\
\text { induce apoptosis }\end{array}$ & $\begin{array}{l}\text { Increase the activities of caspase- } 3 \text {, caspase- } 8 \text {, } \\
\text { and caspase- } 9\end{array}$ & Zheng et al. (2020) \\
\hline & HCT116, НCT-8 & In vitro & & & $\begin{array}{l}\text { Zhang L. et al. (2019) } \\
\text { ntinued on following page) }\end{array}$ \\
\hline
\end{tabular}


TABLE 1 | (Continued) The detailed role of UA and cancer.

\begin{tabular}{|c|c|c|c|c|c|}
\hline $\begin{array}{l}\text { Types of } \\
\text { cancer }\end{array}$ & Cell line used & $\begin{array}{l}\text { Study } \\
\text { type }\end{array}$ & Therapeutic effect & Mechanism of action & References \\
\hline & & & $\begin{array}{l}\text { Inhibit cell proliferation and } \\
\text { angiogenesis }\end{array}$ & $\begin{array}{l}\text { Regulate the TGF- } \beta 1 / Z E B 1 / \text { miR-200c signaling } \\
\text { pathway }\end{array}$ & \\
\hline & SW620, HCT116 & In vitro & $\begin{array}{l}\text { Inhibit cell proliferation and } \\
\text { metastasis }\end{array}$ & $\begin{array}{l}\text { Inhibit the biomakers of EMT including E-cadherin, } \\
\text { Vimentin, Integrin, Twist, and Zeb1 }\end{array}$ & Wang et al. (2019) \\
\hline & НCT116, НТ29 & In vitro & Induce apoptosis & $\begin{array}{l}\text { Up-regulate the expression levels of MicroRNA- } \\
4500 \\
\text { Inhibit the phosphorylation of JAK2/STAT3 }\end{array}$ & Kim et al. (2018) \\
\hline & $\begin{array}{l}\text { SW480, SW620, LoVo, } \\
\text { RKO, SW620 xenograft } \\
\text { mouse model }\end{array}$ & $\begin{array}{l}\text { In vitro, } \\
\text { in vivo }\end{array}$ & $\begin{array}{l}\text { Inhibit cell proliferation } \\
\text { Induced apoptosis }\end{array}$ & 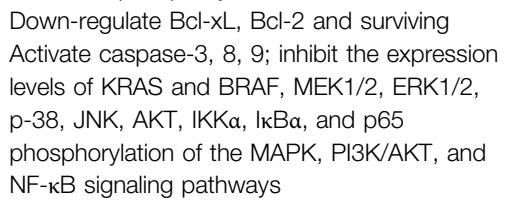 & Shan et al. (2016) \\
\hline & CaCo-2 & In vitro & Induced apoptosis & Activate the expression of Caspase 3 & Omoyeni et al. (2015) \\
\hline & $\begin{array}{l}\text { HT-29, CRC mouse } \\
\text { xenograft model }\end{array}$ & $\begin{array}{l}\text { In vitro, } \\
\text { in vivo }\end{array}$ & Inhibit angiogenesis & $\begin{array}{l}\text { Inhibit the expressions of VEGF-A and bFGF } \\
\text { Suppress the activation of SHH, STAT3, akt and } \\
\text { p70S6K pathways }\end{array}$ & Lin et al. (2013a) \\
\hline & $\begin{array}{l}\text { HT-29, CRC mouse } \\
\text { xenograft model }\end{array}$ & $\begin{array}{l}\text { In vitro, } \\
\text { in vivo }\end{array}$ & Inhibit cell proliferation & $\begin{array}{l}\text { Modulate the expressions of Cyclin D1, CDK4 } \\
\text { and p21 }\end{array}$ & Lin et al. (2013b) \\
\hline & & & Induced apoptosis & $\begin{array}{l}\text { alter the ratio of } \mathrm{Bax} / \mathrm{Bcl}-2 \text {; activate of several } \\
\text { CRC-related signal transduction cascades } \\
\text { including STAT3, ERK, JNK and p38 }\end{array}$ & \\
\hline & & & Inhibit tumor growth & & \\
\hline & $\begin{array}{l}\text { HCT15, Nude mice } \\
\text { xenografted with HCT15 } \\
\text { cells }\end{array}$ & $\begin{array}{l}\text { In vitro, } \\
\text { in vivo }\end{array}$ & $\begin{array}{l}\text { Induce cell death } \\
\text { Modulate autophagy }\end{array}$ & Activate the JNK pathway & Xavier et al. (2013) \\
\hline & $\begin{array}{l}\text { Orthotopic nude mouse } \\
\text { model }\end{array}$ & In vivo & $\begin{array}{l}\text { Inhibit cell growth and } \\
\text { metastasis }\end{array}$ & 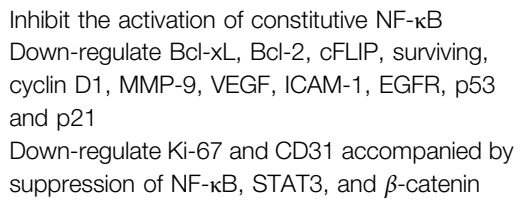 & Prasad et al. (2012) \\
\hline & HT-29 & In vitro & Induce apoptosis & Activate the $\mathrm{P} 2 \mathrm{Y} 2 / \mathrm{Src} / \mathrm{p} 38 / \mathrm{COX}-2$ pathway & Limami et al. (2012) \\
\hline \multirow[t]{6}{*}{ Liver Cancer } & HepG2 & In vitro & Inhibit cell survival & - & $\begin{array}{l}\text { (Lam et al., 2019; Ngo et al., } \\
\text { 2019) }\end{array}$ \\
\hline & HepG2, 7721, HuH7 & In vitro & Inhibit cell growth & $\begin{array}{l}\text { Down-regulate the expression of downstream } \\
\text { target genes of STAT3, such as Bcl-2, Bcl-xl and } \\
\text { surviving }\end{array}$ & Liu et al. (2017) \\
\hline & HepG2 & In vitro & Inhibit cell growth & $\begin{array}{l}\text { Inhibit growth through AMPKa-mediated } \\
\text { reduction of DNA methyltransferase } 1\end{array}$ & Yie et al. (2015) \\
\hline & HepG2 & In vitro & Induce apoptosis & activate the phosphorylation of AMPK and GSK3 $\beta$ & Son et al. (2013) \\
\hline & Нер3B, HuH7, HA22T & & $\begin{array}{l}\text { Inhibit invasiveness and } \\
\text { metastasis }\end{array}$ & $\begin{array}{l}\text { Decrease the levels of VEGF, IL-8, ROS and NO } \\
\text { Retain the level of glutathione }\end{array}$ & Lin et al. (2011) \\
\hline & SMMC-7721 & & Induce apoptosis & Activate p53-dependent pathway & Yu et al. (2010) \\
\hline \multirow[t]{2}{*}{$\begin{array}{l}\text { Prostate } \\
\text { Cancer }\end{array}$} & LNCaP & In vitro & Induce apoptosis & $\begin{array}{l}\text { Activate caspase-3/9 via mediation of ROCK1/ } \\
\text { PTEN-cofilin-1/cytochrome c protein expression }\end{array}$ & Mu et al. (2018) \\
\hline & $\begin{array}{l}\text { LNCaP, PC-3 xenograft } \\
\text { mouse model with LNCaP/ } \\
\text { PC-3 cells }\end{array}$ & $\begin{array}{l}\text { In vitro, In } \\
\text { vivo }\end{array}$ & Induce apoptosis & $\begin{array}{l}\text { Decrease the levels of } \mathrm{Bcl}-2, \mathrm{Bcl}-\mathrm{xl} \text {, and surviving } \\
\text { Activate caspase-3; activate the } \mathrm{Pl} 3 \mathrm{~K} / \mathrm{Akt} / \mathrm{mTOR} \\
\text { pathway }\end{array}$ & Meng et al. (2015) \\
\hline \multirow[t]{2}{*}{$\begin{array}{l}\text { Renal } \\
\text { Cancer }\end{array}$} & A498 & In vitro & Inhibit invasiveness & $\begin{array}{l}\text { Up-regulate the expression levels of NLRP3, } \\
\text { caspase- } 1 \text { and IL-1 } \beta\end{array}$ & Chen et al. (2020) \\
\hline & $786-0$ & In vitro & $\begin{array}{l}\text { Induce cell cycle arrest } \\
\text { Induce apoptosis }\end{array}$ & $\begin{array}{l}\text { Inhibit the activation of STAT3 and the } \\
\text { expressions of p21 and p } 27\end{array}$ & Li W. et al. (2017) \\
\hline
\end{tabular}

Abbreviations ADP, adenosine diphosphate; AIF, apoptosis-inducing factor; AKT, protein kinase B; AMPK, adenosine 5'-monophosphate (AMP)-activated protein kinase; ATP, adenosine triphosphate; Bax, Bcl-2-associated X protein; Bcl-2, B-cell lymphoma-2; Bcl-xL, B-cell Lymphoma/Leukemia-XL; bFGF, basic fibroblast growth factor; BRAF, v-raf murine sarcoma viral oncogene homolog B1; CDK, cyclin-dependent kinases; CFLIP, Fas-associated death domain-like interleukin-1 $\beta$-converting enzyme (FLICE)-like inhibitory protein; CHOP, endoplasmic reticulum stress pathway marker protein; COX, cyclooxygenase; DNMT1, DNA (cytosine-5)-methyltransferase 1; EGFR, epithelial growth factor receptor; EMT, epithelial-mesenchymal transition; ER, endoplasmic reticulum; ERK, extracellular regulated protein kinases; EZH2, enhancer of zeste 2 polycomb repressive complex 2 subunit; GSK, glycogen synthase kinase; HK, hexokinase; ICAM, intercellular adhesion molecule; IKK, inhibitor of nuclear factor kappa-B kinase; IL, interleutin; JAK, Janus kinase; JNK, jun N-terminal kinase; Keap1, Keal-like ECHassociated protein 1; KRAS, V-Ki-ras2 Kirsten ratsarcoma viral oncogene homolog; MAPK, mitogen-activated protein kinase; MEK1/2, MAP kinase kinase 1/2; MMP, matrix metalloproteinase; mTOR, mammalian target of rapamycin; NF-kB, nuclear factor kappa-B; NLRP3, NLR family pyrin domain-containing 3; NO, nitric oxide; Nrf, nuclear factor E2-related factor; PCNA, proliferating cell nuclear antigen; p-ERK, phosphorylated extracellular regulated protein kinases; PI3K, phosphoinositide 3-kinase; PKM2, pyruvate kinase; PLK, polo-like kinase; PMA, phorbol myristate acetate; $p$-p38, phosphorylated 038 mitogen-activated protein kinase; PTEN, phosphatase and tensin homolog; P2Y2, specific purinergic receptors belonging to the P2Y families; RAF, RAF serine/threonine kinase protein; ROCK, Rho-associated protein kinase; ROS, reactive oxygen species; SAPK, stress-activated protein kinase; SHH, sonic hedgehog; Src, Src protein tyrosine kinase; STAT, signal transducers and activators of transcription; TGF- $\beta 1$, Transforming growth factor- $\beta 1$; UA, ursolic acid; VEGF, vascular endothelial growth factor; ZEB1, zinc finger E-box-binding homeobox. 


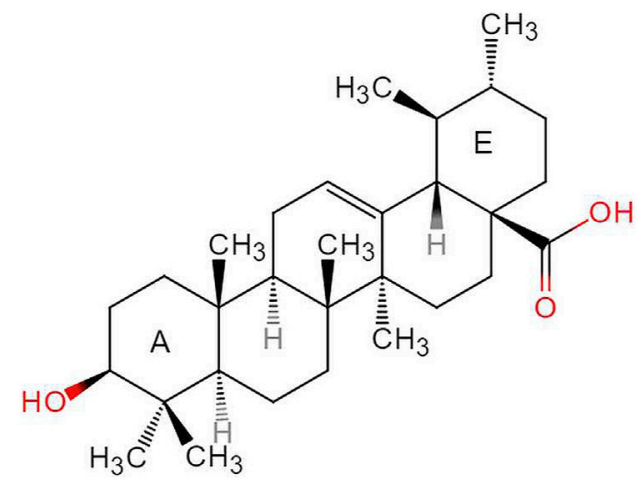

FIGURE 2 | The structure of ursolic acid.

culture, but no significant conversion has been observed in the absence of NADPH (Qin and Wang, 2019). A pharmacodynamic test showed that after administering $19.69 \mathrm{mg} / \mathrm{kg}$ UA to healthy Sprague-Dawley rats, some kinetic parameters measured as follows: apparent volume of distribution (V/F $0.0169 \pm 0.0030 \mathrm{~L} / \mathrm{g}$ ), half-life time distribution $\left(t_{1 / 2 \alpha} 6.95 \pm 1.42 \mathrm{~h}\right)$, half-life time elimination $\left(t_{1 / 2 \beta} 40.94 \pm 4.91 \mathrm{~h}\right)$, and maximum plasma concentration $\left(C_{\max } 487.47 \pm 138.94 \mathrm{ng} / \mathrm{ml}\right)$ (Chen X. et al., 2018). These results could be related to molecular proteins that affect UA metabolism. Studies have shown that 611 molecular proteins may interact with UA, and more than 49 functional clusters respond to UA (He et al., 2015). Experiments have shown that, compared with other small molecules, UA has a relatively lower $\log P$ value and better lipophilicity, thus it has a better chance to reach the receptor site. Lipophilicity is one of the major determinants of a compound's metabolic properties in vivo, which usually estimated by $\log P$ (Kalani et al., 2012). In the study of pharmacokinetics, elimination includes two parts: metabolism and excretion. However, there are a few studies on UA excretion. Due to the undetectable UA concentration in urine in some extent, which is below the lower limit for quantitative determination (Jinhua, 2019).

However, it is worth noting that owing to the low solubility of $\mathrm{UA}$, some residues remain in the digestive tract after oral administration, and the intestinal microflora may metabolize UA. The intestinal tract has a special microbiome, which is different from the physiological environment of the liver. Therefore, the metabolic transformation process of UA in the intestinal tract is specific and worthy of further study. The results of the study on UA and intestinal flora showed that UA could reduce the dosage of antimicrobials by 8 times (Dwivedi et al. 2015). UA has a good regulatory effect on intestinal microflora; it can regulate the intestinal microbial community of hamsters and promote the growth of short-chain fatty acid-producing bacteria in the intestinal tract (Hao et al., 2020).

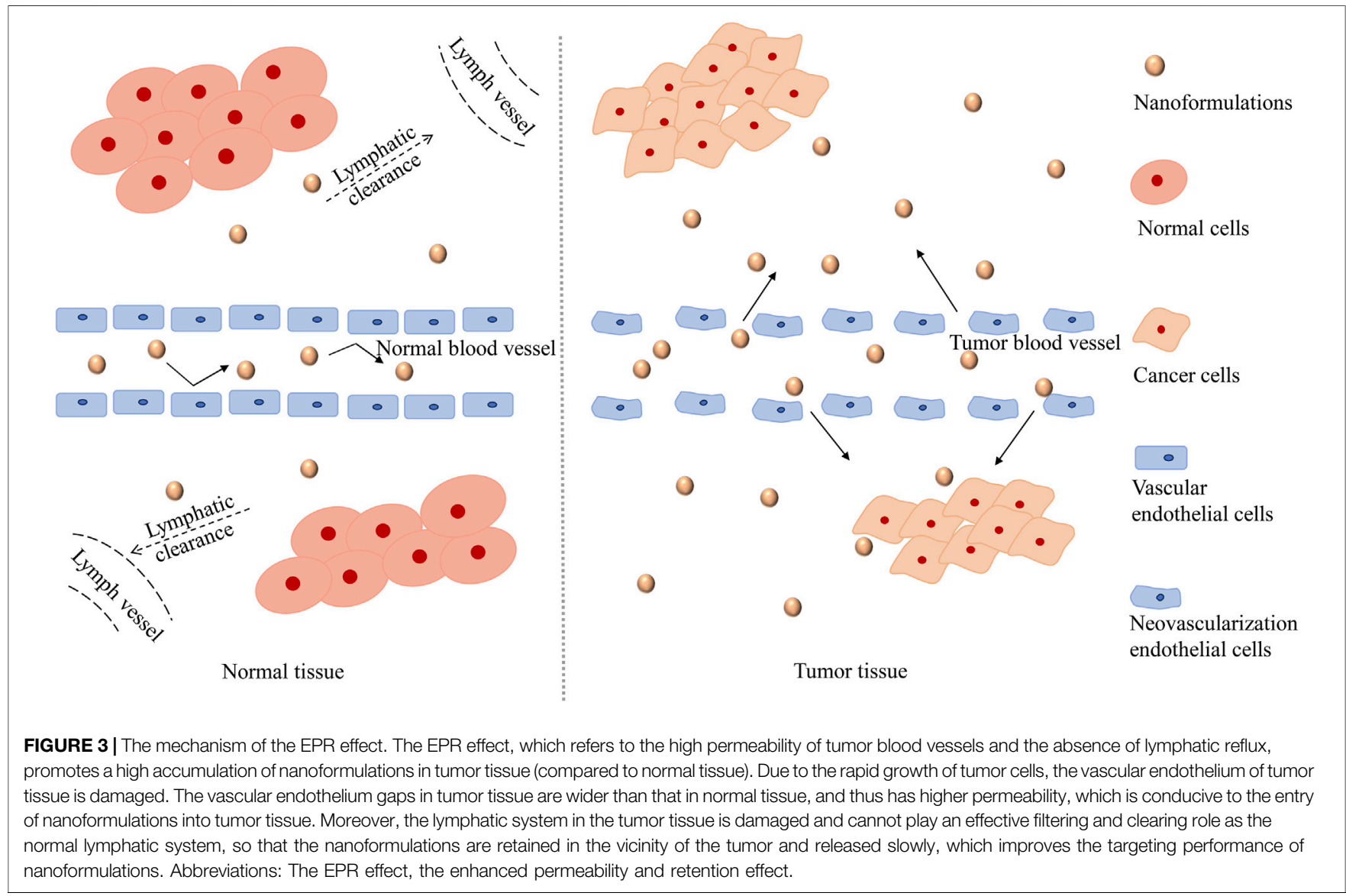


In summary, UA is a hydrophobic drug with poor solubility and oral bioavailability. Hence, it is difficult to exert significant cytotoxic activity. UA is absorbed rapidly by the intestinal tract mainly through passive diffusion, and is also affected by exogenous protein $\mathrm{P}$-glycoprotein or $\beta$-glucuronidase or sulfate esterase, resulting in poor absorbed blood content. UA is mainly distributed in liver after absorption, which may be related to the transport mediated by OATPs. The concentration of UA in the liver and kidney is increased in a time dependent manner, which may be related to blood perfusion. The metabolism of UA in liver is closely related to the enzyme activity of CYP and NADPH. According to existing studies, we know that only a very small amount of UA is eliminated by renal excretion. Up to now, the pharmacokinetic study of UA still needs further exploration.

\section{REVIEW OF UA NANOFORMULATIONS}

As the gastrointestinal mucosa permeability of UA is poor and its oral absorption rate is low, the UA-related nanoformulations are designed so as to be administered mainly intravenously to prevent the gastrointestinal absorption process of UA and improve the drug delivery efficiency to the site of action. The basic characteristics and related anticancer research results of UA nanoformulations are shown in Table 2. As was mentioned earlier, nanoformulations selectively accumulate in tumor tissues owing to the EPR effect. Particle size, surface performance, and stability are the three key characteristics of nanoformulations, which affect the accumulation of nanoformulations in tumor tissues (Israel, 2018). As far as the particle size is concerned, it is intended to facilitate the longer blood circulation duration and tumor enrichment of the nanomedicine, while slowing down the excretion from the kidney. Moreover, by modifying surface performance, nanoformulations can be able to evade the immune system, while circulating in the blood system to obtain long circulation performance, so as to increase their chances of flowing through tumor blood vessels and infiltrating into tumor tissues owing to the EPR effect. Regarding stability, in addition to the active drug release required to function in cells, drug molecules must be stably contained in the carrier for the rest of the time so as not to release to the circulatory system or nontarget organs (Nakamura et al., 2015; Nakamura et al., 2016; Kalyane et al., 2019).

It should be noted that the enrichment of nanoformulations into tumor tissues is inevitable through the tumor microenvironment, where the $\mathrm{pH}$ value is more acidic than that of normal tissues, and tumor tissues and their cells contain higher concentrations of glutathione (GSH), reactive oxygen species (ROS), and highly expressed metabolic enzymes (Zhang et al., 2020b). Thus, it could be suggested that the design of nanoformulations should enable them to change their nanometer size, surface, and stability with changes in the blood system, tumor tissues, and the microenvironment of tumor cells, so as to be able to target tumor tissues and reach them efficiently. The property conversion of the nanoformulations can be realized by properties containing many of the same or different functional groups (Schmidt et al., 2018; Cuevas-Flores et al., 2020).

\section{Polymer Micelles of UA}

Polymer micelles are new nanocarriers formed by the selfassembly of copolymers in aqueous solutions. They are usually amphiphilic and have a nucleus-shell structure with a hydrophobic core and a hydrophilic shell (Masserini, 2013; Du and Chen, 2019). The hydrophobic core of micelles can contain hydrophobic antitumor drugs and can increase the solubility and stability of the drugs. The hydrophilic shell can prevent the phagocytosis of the reticuloendothelial system (RES) and keep it stable in the blood circulation for a long time (Li Z. et al., 2018; Ma et al., 2019).

Zhou et al. prepared a UA-loaded polymer micellar delivery system (UA-PMs) using mPEG-PLA (PEG hydrophilic, PLA hydrophobic) by membrane dispersion, and investigated its the proliferation inhibition effect on HepG2 (human liver cancer cells), L-02 (human normal liver cells), and H22 (mouse liver cancer cells) cell lines. The ratio of UA to the carrier was approximately 1:10, and the micelle was smooth and spherical. The average particle size, zeta potential, polymer dispersion coefficient, and the critical micelle concentration was $29.35 \pm 0.38 \mathrm{~nm},-0.75 \pm 1.30 \mathrm{mV}$, $0.299 \pm 0.005$, and $2.3 \times 10^{-3} \mathrm{mg} / \mathrm{mL}$, respectively, which showed good micelle stability and increased circulation time in the blood. In addition, the release of the UA-PMs at $\mathrm{pH} 7.4$ and 5.5 was evaluated at $37^{\circ} \mathrm{C}$ owing to the microenvironment of the tumor tissues with microacidic properties. The results showed that the UA release of the UA-PMs was significantly comparable ( $\mathrm{pH}=5.5,24 \mathrm{~h}, 65 \%$ vs. $\mathrm{pH}=7.4,96 \mathrm{~h}, 50 \%)$ and there was no obvious initial outburst, indicating that the micelles had controlled release behavior and could increase the accumulation of UA at tumor sites to some extent. This could be because UA is protected from degradation by the polymer micellar hydrophobic core. In addition, compared with free UA, the proliferation and migration ability of HepG2 cells are reduced to a certain extent with the increase in the UA-PM concentration. Moreover, neither free UA nor UAPMs are significantly toxic to L-02 cell lines. Interestingly, UA and UA-PMs promote L-02 cell proliferation at low concentrations (approximately $<60 \quad \mathrm{um}$ ). In animal experiments, UA-PMs showed stronger tumor inhibition than free UA at the same concentration; additionally, they showed a concentration-dependent tumor inhibition rate (Zhou et al., 2019).

To improve the controllability and tumor targeting of polymer micelles, it is necessary to make them more sensitive to microenvironmental changes. Therefore, research on polymer micelles has been undertaken in multiple directions (Chen et al., 2014). Different ligands or related antibodies can be modified on the surface of polymer micelles, or materials can be used to make the micelles sense changes in the microenvironment, such as, $\mathrm{pH}$ and oxidative stress in vivo, so as to meet the requirements of targeted and controlled release (Zhang et al., 2016). 
TABLE 2 | The preparation, characteristics, and results about the anti-cancer effects of UA nanoformulations.

\begin{tabular}{lllllll}
\hline Type & Preparation & $\begin{array}{c}\text { Materials or } \\
\text { modified }\end{array}$ & $\begin{array}{c}\text { Particle } \\
\text { size } \mathbf{( n m )}\end{array}$ & $\begin{array}{c}\text { Zeta } \\
\text { potential } \\
\mathbf{( m V}\end{array}$ & $\begin{array}{c}\text { Polydispe- } \\
\text { rsity index }\end{array}$ & Experimental models \\
\hline $\begin{array}{l}\text { Polymer } \\
\text { micelles }\end{array}$ & $\begin{array}{l}\text { The thin-film } \\
\text { dispersion method }\end{array}$ & mPEG-PLA & $\begin{array}{l}29.35 \pm \\
0.38\end{array}$ & $0.75 \pm 1.30$ & $0.299 \pm 0.005$ & HepG2 cells \\
\hline
\end{tabular}

Inhibit the proliferation and migration

HepG2 cells; (The I $\mathrm{C}_{50}$ values of free UA and

$\mathrm{UA}$-PMs at $24 \mathrm{~h}$ were $43.2 \pm 5.01$ and

L-02 cells,

Reg $\pm 2.44 \mathrm{mmol} / \mathrm{L}$, respectively.)

Regulate the growth of $\mathrm{L}-02$ cells,

bidirectionally

H22 cells implanted tumor xenograft in Inhibit the growth of $\mathrm{H} 22$ xenograft and male Kunming mice prolong the survival time of tumor-bearing mice. (The tumor inhibition rate was $61.43 \%$, and the survival time was increased to $45.6 \pm$ 10.0 days, with $100 \mathrm{mg} / \mathrm{kg}$ UA-PMs,

respectively.)

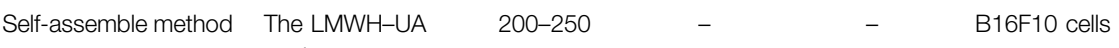
conjugate

Subcutaneously implanted B16F10 cells tumor xenografts in female C57BL/6 mice

EC-304 cells method

The lipid hydration method

Long-circulating and $\mathrm{pH}$-sensitive

$191.1 \pm 6.4$ $1.2 \pm 1.4$

MDA-MB-231 cells, LNCaP cells

Enhance neutralzi

Cheng W. et al. th factors

growth and prevent

recurrences without risk of hemorrhage. (The inhibition ratios of LMWH-UA, LMWH + UA and LMWH were $41.89,30.11$ and $26.28 \%$, respectively.)

Significantly extend the circulation time

Possess higher stability and slower release rate than conventional liposomes

Possess relatively low cytotoxic effect than $U A$ conventional liposomes within $24 \mathrm{~h}(71.26 \%$ vs. $68.27 \%)$

Significantly inhibit cancer cell proliferation.

on MDA-MB-231 cells were $13.07 \pm 1.54$ and et al. (2013)

$8.13 \pm 2.3 \mu \mathrm{mol} / \mathrm{L}$ respectively. However,

there was no statistical significance for $\mathrm{LNCaP}$

cells.)

The lipid hydration method

Long-circulating and $\mathrm{pH}$-sensitive

$182.7 \pm 8.0$

$0.3 \pm 1.6$

$0.60 \pm 0.07$

MCF-7 tumor-bearing mice

liposome

The thin-film dispersed FA-modified

$160.1 \pm$

$21.24 \pm 4.2 \quad 0.196 \pm 0.052$

hydration method

12.5

$\mathrm{KB}$ cells, Subcutaneously implanted

$\mathrm{KB}$ cells tumor xenografts in female

Balb/c nu/nu mouse

Seem to induce an antiangiogenic effect in the

human breast tumor model

Rocha et al.

Tumor growth inhibition was not observed in

human breast tumor-bearing animals

Induce more cytotoxicity and higher

apoptosis

Significantly higher human epidermoid

carcinoma (KB) inhibition. (The $\mathrm{IC}_{50}$ values of

FTL-UA and FR blocking group were 22.05

and $65.66 \mu \mathrm{M}$, respectively.)

Significant inhibition of cell growth; (The

hydration method Bmi1 siRNA

Bmi1 siRNA

inhibition rate was $71 \%$.)

Human KB tumor xenograft nude mice Significant positive correlation between Bmi1siRNA and UA co-delivered by folatetargeted liposomes to inhibit tumor cells and revealed enhanced cytotoxic effects (The 
TABLE 2 | (Continued) The preparation, characteristics, and results about the anti-cancer effects of UA nanoformulations.

\begin{tabular}{|c|c|c|c|c|c|c|c|c|}
\hline Type & Preparation & $\begin{array}{l}\text { Materials or } \\
\text { modified }\end{array}$ & $\begin{array}{l}\text { Particle } \\
\text { size }(n \mathrm{~nm})\end{array}$ & $\begin{array}{c}\text { Zeta } \\
\text { potential } \\
(\mathrm{mV})\end{array}$ & $\begin{array}{l}\text { Polydispe- } \\
\text { rsity index }\end{array}$ & Experimental models & Main outcomes & References \\
\hline & & & & & & & $\begin{array}{l}\text { tumor volumes of normal saline group, free } \\
\text { UA group, UA-L group, FA-UA-L group, and } \\
\text { F-UA/siRNA-L group were } 2,254,1,300 \text {, } \\
1,156,753 \text {, and } 318 \mathrm{~mm}^{3} \text {, respectively.) }\end{array}$ & \\
\hline & $\begin{array}{l}\text { The ethanol injection } \\
\text { method }\end{array}$ & CS-modified & $\begin{array}{c}135.4 \pm \\
0.636\end{array}$ & 7.8 & 0.2 & $\begin{array}{l}\text { HeLa cells } \\
\text { Mice bearing U14 cervical cancer }\end{array}$ & $\begin{array}{l}\text { Reduce the drug dosage and side effects } \\
\text { Exhibit obvious anti-proliferative effect } \\
\text { ( } 76.46 \% \text { on HeLa cells) and significantly } \\
\text { antitumor activity } \\
\text { Enhanced cell apoptosis, extensive necrosis } \\
\text { and low cell proliferation activity (61.26\% in } \\
\text { mice bearing U14 cervical cancer) }\end{array}$ & $\begin{array}{l}\text { Wang M. et al. } \\
(2017)\end{array}$ \\
\hline & $\begin{array}{l}\text { The ethanol injection } \\
\text { method }\end{array}$ & PLL, HA & $102.0 \pm 3.0$ & $-8.5 \pm 1.1$ & $0.254 \pm 0.028$ & SCC-7 cells & $\begin{array}{l}\text { Achieve the programmed apoptosis for } \\
\text { anticancer action }\end{array}$ & $\begin{array}{l}\text { Poudel et al. } \\
(2020)\end{array}$ \\
\hline & & & & & & BT-474 cells & $\begin{array}{l}\text { Exhibit pronounced anticancer effect. (In } \\
\text { SCC- } 7 \text { cells, the cell viabilities treated with UA } \\
\text { and UA-PLL-HA.P at } 48 \mathrm{~h} \text { were about } 41 \text { and } \\
21 \% \text {, respectively; under the same } \\
\text { conditions, in BT- } 474 \text { cells, the cell viabilities } \\
\text { were about } 40 \text { and } 33 \% \text {, respectively.) }\end{array}$ & \\
\hline Nanoemulsion & Mechanical method & $\mathrm{OA}, \cup \mathrm{A}$ & $\begin{array}{l}198.95 \pm \\
21.34\end{array}$ & - & $0.285 \pm 0.053$ & B-16 cells & $\begin{array}{l}\text { Significantly high antioxidant (>85\%) and anti- } \\
\text { cancer activity (The cytotoxic activity of the } \\
\text { compound decreased from } 17.4 \text { to } 2.9 \mu \mathrm{M} \\
\text { after making nanoemulsion.) }\end{array}$ & $\begin{array}{l}\text { Alvarado et al. } \\
\text { (2018) }\end{array}$ \\
\hline \multirow[t]{4}{*}{ Nanocrystals } & $\begin{array}{l}\text { The anti-solvent } \\
\text { precipitation method }\end{array}$ & UA & $188.0 \pm 4.4$ & $-25.0 \pm 5.9$ & $0.154 \pm 0.022$ & MCF-7 cells & $\begin{array}{l}\text { Showed good aqueous dispensability and a } \\
\text { higher dissolution rate } \\
\text { Significantly induce stronger cell growth } \\
\text { inhibition activity by inducing G2/M phase cell } \\
\text { cycle arrest. (The I } \mathrm{C}_{50} \text { values of free UA and } \\
\text { UA nanocrystals at } 24 \mathrm{~h} \text { were } 15.42 \pm 1.19 \\
\text { and } 7.90 \pm 1.11 \mu \mathrm{mol} / \mathrm{L} \text {, respectively.) }\end{array}$ & Song et al. (2014) \\
\hline & $\begin{array}{l}\text { The high pressure } \\
\text { homogenization } \\
\text { method }\end{array}$ & UA & $291.7 \pm 7.5$ & $-14.0 \pm 1.9$ & $0.260 \pm 0.021$ & Sprague-Dawley rats & $\begin{array}{l}\text { a significant increase was observed in the } \\
\text { dissolution rate of UA nanocrystals } \\
\text { The relative bioavailability of UA nanocrystals } \\
\text { exhibited 2.56-fold enhancement than that of } \\
\text { UA coarse suspension }\end{array}$ & Pi et al. (2016) \\
\hline & $\begin{array}{l}\text { The antisolvent } \\
\text { precipitation method }\end{array}$ & UA & $\begin{array}{c}101.2 \pm \\
3.53\end{array}$ & $\begin{array}{l}-9.79 \pm \\
0.794\end{array}$ & & MCF-7 cells & $\begin{array}{l}\text { Compared with the UA solution-treated cells, } \\
\text { the population of MCF- } 7 \text { cells in the early and }\end{array}$ & $\begin{array}{l}\text { Wang et al. } \\
(2015)\end{array}$ \\
\hline & & & $\begin{array}{c}299.8 \pm \\
6.63\end{array}$ & $\begin{array}{l}-8.19 \pm \\
0.782\end{array}$ & $0.150 \pm 0.021$ & & $\begin{array}{l}\text { late apoptotic phases was increased } \\
\text { respectively by } 49 \text { and } 52 \% \text { when treated with } \\
\text { the } 100 \mathrm{~nm} \text { nanosuspension and } 82 \text { and } 69 \% \\
\text { when treated with the } 300 \mathrm{~nm} \\
\text { nanosuspension }\end{array}$ & \\
\hline Nanoparticles & $\begin{array}{l}\text { Nano-precipitation } \\
\text { method }\end{array}$ & CS & 100-200 & 41.6 & 0.08 & HUVECS & $\begin{array}{l}\text { Inhibit the proliferation, migration, and tube } \\
\text { formation of HUVECs; (The } \mathrm{IC}_{50} \text { of UA and } \\
\mathrm{CH}-U A-N P s \text { was } 82.5 \text { and } 56.7 \mu \mathrm{g} / \mathrm{ml} \text {, } \\
\text { respectively.) }\end{array}$ & Jin et al. (2016b) \\
\hline
\end{tabular}


TABLE 2 | (Continued) The preparation, characteristics, and results about the anti-cancer effects of UA nanoformulations.

\begin{tabular}{|c|c|c|c|c|c|c|}
\hline Type & Preparation & $\begin{array}{l}\text { Materials or } \\
\text { modified }\end{array}$ & $\begin{array}{l}\text { Particle } \\
\text { size }(\mathrm{nm})\end{array}$ & $\begin{array}{c}\text { Zeta } \\
\text { potential } \\
\text { (mV) }\end{array}$ & $\begin{array}{l}\text { Polydispe- } \\
\text { rsity index }\end{array}$ & Experimental models \\
\hline & & & & & & CAM \\
\hline & & & & & & $\begin{array}{l}\text { BALB/c mice vaccinating ascite } \\
\text { mouse } \mathrm{H} 22 \text { cells }\end{array}$ \\
\hline & $\begin{array}{l}\text { Nano-precipitation } \\
\text { method }\end{array}$ & FA-modified, CS & 160 & 39.3 & - & MCF-7 cells \\
\hline
\end{tabular}

Main outcomes

References

method

MCF-7 xenograft mouse model

Reduce the angiogenesis in CAM of fertilized eggs; (CH-UA-NPs at $2 \mu \mathrm{g} / \mathrm{CAM}$ could

effectively reduce angiogenesis as compared with that of control group.)

Inhibit the H22 tumor growth through antiangiogenesis induced by VEGF signaling pathway blocking. (The volume of tumors of nanoparticle-treated group and control group was $1.12 \pm 0.12$ and $2.36 \pm 0.32 \mathrm{~cm}^{3}$ ) Effectively diminish off-target effects and increase local drug concentrations of UA Induce overproduction of ROS and destruction of mitochondrial membrane potential, and resulted in the irreversible apoptosis in cancer cells. (The tumor weight of FA-CS-UA-NPS group, UA group and normal saline control group was $2.1 \pm 1.02 \mathrm{~g}$, $3.48 \pm 0.24 \mathrm{~g}$ and $5.26 \pm 1.69 \mathrm{~g}$, respectively.) Reduce the cell viability in $70 \%$ after $72 \mathrm{~h}$

Antônio et al. (2017)

solvent evaporation

$246 \pm 10$

$-24.6 \pm 3.1$

$0.148 \pm 0.014$

B16-F10 cells

PVP-b-PCL

$120.0 \pm 4.0 \quad-0.96 \pm 0.3$

Nano-precipitation

method
Single-emulsion

solvent evaporation

technique
H22 cells, Subcutaneously implanted H22 cells tumor xenografts in male ICR mice

B16-F10 cells

HepG2 cells
Inhibit the growth of liver cancer cells and

induced cellular apoptosis more efficiently

than did free UA; $\left(\mathrm{IC}_{50}, 32.89 \pm 3.23 \mu \mathrm{M}\right.$ vs.

$59.84 \pm 4.12 \mu \mathrm{M}$; CT findings confirmed that the tumor lesions in the UA-NPS group

showed near total depletion.)

Significantly delayed tumor growth

More significant effect on protein expression than did free UA

Upregulated the expressions of Caspase-3 and Bax, but downregulated the expressions of $\mathrm{BCl}-2$ and $\mathrm{COX}-2$

Exhibit slower blood clearance and

comparatively high uptake in tumor region Exhibit dose-dependent activity in

comparison to free drug. (The $\mathrm{IC}_{50}$ values of free UA and UA-NPs were 60 and $18 \mu \mathrm{M}$ respectively following $48 \mathrm{~h}$ incubation.)

Exhibit sustained release profile in the

initial $20 \mathrm{~h}$

Exhibit higher proliferation inhibition, cell cycle arrest at the G2/M phase and significantly caused the early and late apoptosis in HepG2 cells. (The early and late apoptosis rates of HepG2 cells treated with control group, UA 
TABLE 2 | (Continued) The preparation, characteristics, and results about the anti-cancer effects of UA nanoformulations.

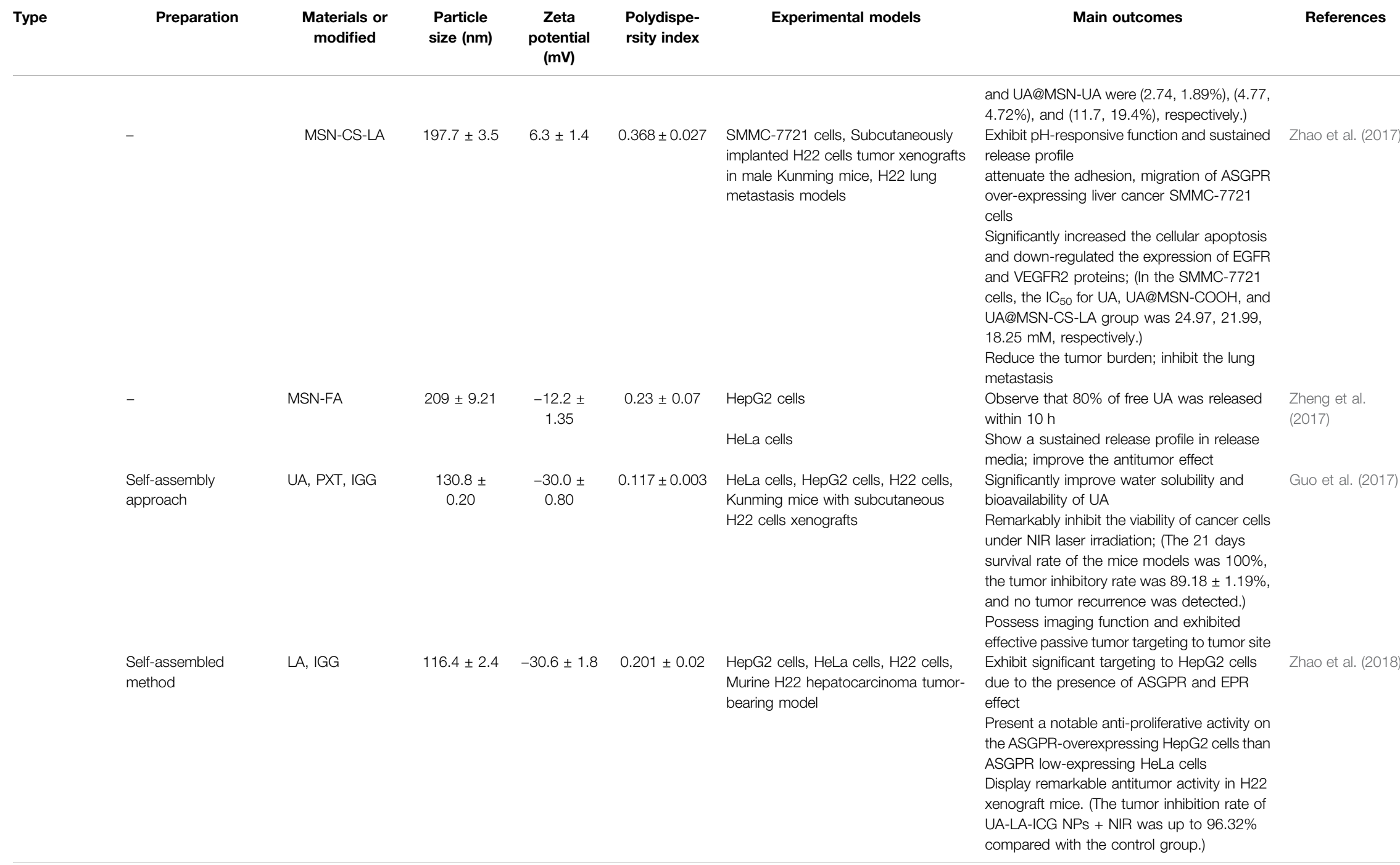

Abbreviations ASGPR, asialoglycoprotein receptor; BCl-2, B-cell lymphoma-2; Bax, BCl-2-associated X protein; CAM, chicken chorioallantoic membrane; COX, cyclooxygenase; CS, chitosan; EGFR, epidermal growth factor receptor; EPR, enhanced permeability and retention effect; FA, folate; HA, hyaluronic acid; HUVECS, human umbilical vascular endothelial cells; IGG, indocyanine green; LA, lactobionic acid; LMWH, Iow molecular weight heparin; mPEG, methoxy poly (ethylene glycol); MSN, mesoporous silica nanoparticle; NIR, near-infrared; OA, oleanolic acid; PCL, poly (e-caprolactone); PLA, poly(L-lactic acid); PLGA, Polylactic-co-glycolic acid; PLL, poly-L-lysine; PVP, poly(N-viny/pyrrolidone); PXT, paclitaxel; ROS, reactive oxygen species; UA, ursolic acid; VEGF, vascular endothelial growth factor; VEGFR, vascular endothelial growth factor receptor. 


\section{UA Liposomes}

Liposomes are vesicles composed of one or more lipid bilayers layers, first discovered by British scientist Bangham in the 1960s (Su et al., 2018). Liposomes can carry both hydrophilic (embedded in the lumen of a liposome) and hydrophobic substances (embedded in a lipid hydrophobic bilayer) (Ghadiri et al., 2019). Liposomes have been used for drug delivery since 1971; compared with other nanodelivery systems, liposomes have certain advantages, such as good biocompatibility and degradability as well as low immunogenicity. This constitutes liposomes promising for application in drug delivery (Yang et al., 2017). At present, liposomes have been modified from their initial, classical lipid composition, to develop long-circulating, environmentally sensitive, and actively targeted liposomes; through organic combinations, a multi-functional liposome that has higher clinical application potential has been obtained.

\section{Long Circulating Liposomes}

Liposomes are composed of dynamic phospholipid membranes, which have thermal instability. Moreover, the destruction of proteins and enzymes in the blood environment is not conducive to the stability of the liposome membrane, leading to its rupture and the leakage of the encapsulated drugs (Yan et al., 2016; Tanka-Salamon et al., 2017). In addition, the mononuclear macrophage system (MPS) recognizes and ingests liposomes to reduce the amount of drugs reaching the target site (Martinez et al., 2018). In order to solve the aforementioned problems, polyethylene glycol (PEG)-modified liposomes with good effect and marketization have been employed. PEG molecules can form a hydration film on the surface of liposomes, which is helpful in increasing the resistance and improving the stability of liposomes. In addition, PEG molecules block the interaction between positive charge and proteins, reduce the probability of being recognized and absorbed by MPS, and significantly lengthen the circulation time of liposomes in the body. Therefore, they are called long circulating liposomes (Zeng et al., 2016; Yuba et al., 2018).

It has been confirmed that PEG-modified UA liposomes have higher stability and slower release rates compared with ordinary liposomes. In one study, the ratios of the components of PEGylated UA liposomes were determined; the UA, PEG, cholesterol, and soy lecithin ratio was 3:2:5:30. The UA liposomes showed a regular uniform spherical shape with good dispersion and average particle size between 100 and $200 \mathrm{~nm}$. In addition, after PEGylation, UA liposomes were harder than ordinary liposomes, which, to some extent, prevented them from collapsing in space, further improved their membrane stability, and prevented the sudden release of loading drugs. After a 17-days observation at $25^{\circ} \mathrm{C}$, the encapsulation rates of the modified liposomes and the ordinary liposomes were 63.18 and $55.18 \%$, respectively. Moreover, the modified liposomes could circulate in the blood for $48 \mathrm{~h}$, significantly extending the circulation time and increasing the drug content at the targeted sites. It should be noted that in subsequent in vitro anti-tumor experiments, the modified liposomes did not show a higher tumor inhibition rate than the normal liposomes (68.27 vs. $71.26 \%)$. This may be related to the slow release of liposome drugs after modification, and the increased observation time ( $24 \mathrm{~h}$ of cell culture in vitro in this study), which may yield opposite tumor suppressive results (Zhao et al., 2015).

\section{pH Sensitive Liposomes}

In one study, the $\mathrm{pH}$ value of the extracellular microenvironment of the tumor was between 6.5 and 7.2, which was more acidic than that of normal tissues $(\sim 7.4)$, while the intracellular lysosome $\mathrm{pH}$ was lower than 6.0 ( $\mathrm{Hu}$ et al., 2016). This step change in $\mathrm{pH}$ in tumor tissues has attracted the attention of researchers and led to the design and synthesis of $\mathrm{pH}$-sensitive liposomes based on longcirculating liposomes. The $\mathrm{pH}$-sensitive liposomes are stable under physiological conditions and break the connection bonds when located in an acidic environment, thereby triggering the release of drugs and increasing their release rate in specific tissues as well as improving the targeting of tumor tissues by the drug (Chen et al., 2013). However, it is worth mentioning that researchers have obtained inconsistent results in preclinical studies of breast cancer regarding $\mathrm{pH}$-sensitive liposomes; therefore, further studies are required. Oliveira et al., successfully prepared a long-circulating $\mathrm{pH}$-sensitive liposome (SpHL-UA) with an average particle size of approximately $191.1 \mathrm{~nm}$, which exhibited significant inhibition of MDA-MB-231 cell lines in breast cancer (SpHL-UA, $\mathrm{IC}_{50}$ $8.13 \mu \mathrm{M}$ vs. free $\mathrm{UA}, \mathrm{IC}_{50} 13.07 \mu \mathrm{M}$ ) (Caldeira de Araújo Lopes et al., 2013). However, in another study, tumor growth inhibition was not observed in MCF-7 tumor-bearing mice treated with SpHL-UA (the particle size was approximately $182.7 \mathrm{~nm}$ ) (5 days), but anti-angiogenesis was observed to a certain extent (Rocha et al., 2016). This could have been due to the different models employed or the reduced liposome action time, which may have resulted in absent treatment effects during the observation period.

\section{Actively Targeted Liposomes}

Actively targeted liposomes are prepared by adding some targeting materials to liposomes, which can further increase the accumulation of drugs in tumor tissues. Folic acid (FA) receptors are widely used in targeted delivery systems because of their high expression in many cancer cells and low expression in normal tissues, as well as the high affinity between FA molecules and FA receptors or folate-binding proteins expressed in cell membranes (Yi, 2016; Zhang et al., 2017). By using ligand-receptor specific binding, the anti-cancer UA has been successfully delivered to tumor cells through effective tumor targeting mediated by FA receptors.

One study showed that the average particle size of the folatetargeted UA liposomes was $155 \mathrm{~nm}$, with good stability and nearly 31-fold (compared with the non-targeted liposomes) drug delivery efficiency. Subsequent anti-cancer studies have produced better results. Folate-targeted UA liposomes significantly reduce the tumor volume of tumor-bearing mice (by approximately $55 \%$ ), and their $\mathrm{IC}_{50}$ is significantly lower than that of non-targeted liposomes $(22.05$ vs. $146.3 \mu \mathrm{M})$. Moreover, the cytotoxicity of folate-targeted UA liposomes induced by apoptosis is significantly dose- and time-dependent (Yang 
et al., 2014). In another study targeting UA liposomes with FA, Bmil siRNA (the gene encoding polycomb repressive complex 1; small interfering RNA) was adsorbed on the surface of liposomes in addition to planting FA molecules. The downregulation of Bmil inhibits tumor cell growth in different cancer types, and siRNA can downregulate the expression of oncogenes. Finally, a uniformly stable liposome FA-UA/siRNA-L with an average particle size of approximately $165.1 \mathrm{~nm}$ was successfully prepared. After a 24-h FA-UA/siRNA-L treatment, the inhibition rate of $\mathrm{KB}$ cells (human oral cancer cell line) was $71 \%$. In an antitumor tumor-burdened mice observation experiment, the tumor sizes of the normal saline, free UA, UA liposome, UA folate liposome targeting, and FA-UA/siRNA-L groups were $2,254,1,300,1,156,753$, and $318 \mathrm{~mm}^{3}$, respectively, which suggests that FA targeted liposomes can significantly enhance the UA anti-cancer effect, and UA and Bmil siRNA have some synergistic antitumor effects (Li W. et al., 2019).

In addition to FA molecules, glycosyl-specific binding receptors are also highly expressed in the cell membrane of human tissues. Therefore, it would be worth considering to add polysaccharide-modifying components, such as hyaluronic acid (HA) molecules, in the liposome structure to improve targeting. Sun et al., successfully prepared UA containing nanoliposomes encapsulated in hyaluronic acid, which showed better anti-liver cancer activity than 5-fluorouracil. However, it should be mentioned that UA was not the only drug targeting tissues in this study; ginsenoside and oleanolic acid (OA) were used as well (Sun S. et al., 2020).

\section{Multifunctional Liposomes}

It is worth noting that the tumor microenvironment is complex and changeable, and there may be $\mathrm{pH}$ value, enzyme activity, and ROS content differences overall or depending on the layer. Therefore, a single modification cannot fully cope with the microenvironment and all the accompanying changes. Therefore, in order to achieve higher transmission efficiency and better therapeutic effects, multifunctional liposomes with reasonable superposition of different modification modes have been developed by scientists.

Poudel et al. successfully prepared a new UA nanoliposome with dual $\mathrm{pH}$ and enzyme response through the use of polyL-lysine (PLL) and HA in recent years. This nanoliposome can enable drugs to locate tumor sites more accurately and improve their bioavailability at target sites. PLL is a cation that is $\mathrm{pH}-$ responsive by protonation. $\mathrm{HA}$ is an anion that reacts with hyaluronidase (HYAL) in tumor tissues and enters cells by binding specifically to CD44 receptors. In the aforementioned study, cholesterol (Chl), phosphatidylcholine (PC), and UA were prepared into UA liposomes (UA.P) at a ratio of 1:2:0.5. The particle size and zeta potential were $85.7 \pm 1.5 \mathrm{~nm}$ and $-19.3 \pm 0.2$ $\mathrm{mV}$, respectively. On this basis, UA-PLL.P was constructed by coating the PLL layer with a liposome with a particle size of $91.3 \pm$ $1.1 \mathrm{~nm}$ and zeta potential of $32.6 \pm 0.2 \mathrm{mV}$. Finally, the HA layer was coated with a liposome with a particle size and zeta potential of $102.0 \pm 3.0 \mathrm{~nm}$ and $-8.5 \pm 1.1 \mathrm{mV}$, respectively, to construct UA-PLL-HA.P. The results showed that the sustained release time of UA liposomes was significantly prolonged after surface modification. Additionally, UA-PLL-HA.P had the highest release efficiency of only $38 \%$ at $80 \mathrm{~h}$ under acidic conditions $(\mathrm{pH}=5.0)$, which was due to the protection of the HA layer. After adding HYAL, the release of UA-PLL-HA.P was approximately $70 \%$ within $20 \mathrm{~h}$. Subsequent trials also showed that UA-PLLHA.P had higher cytotoxicity and better anticancer efficacy than UA.P and UA-PLL.P. When the compound UA and two liposomes, UA.P and UA-PLL-HA.P, which were equivalent to $100 \mathrm{~g} / \mathrm{mL} \mathrm{UA}$, were applied to SCC-7 cell lines for $24 \mathrm{~h}$, the cell mortality was 45,51 , and $67 \%$, respectively, and increased to 59 , 65 , and $79 \%$ after $48 \mathrm{~h}$, respectively. Similar results were obtained when the same method was applied to BT-474 cell lines. Despite multiple modifications, the UA liposomes in this experiment also exhibited biphasic release. In other words, multiple modifications resulted in higher sustained release efficiency of UA liposomes compared with a single modification, but the sudden release did not seem to be improved (Poudel et al., 2020).

\section{UA Nanoemulsions}

Nanoemulsion (NE) is a type of thermodynamically stable, colloidal dispersion system spontaneously formed by water and oil phases, surfactants, and co-surfactants in proper proportions (Liu et al., 2016). The surfactant can form an adsorption layer at the oil-water interface; this layer can further prevent the aggregation and flocculation of nanoemulsions through electrostatic repulsion and spatial stability, which greatly enhances the stability of nanoemulsions (Khan et al., 2018; Li Z. et al., 2020). In addition, surfactants can increase the solubility of water-insoluble drugs and promote the entry of drugs into small intestinal epithelial cells. This constitutes nanoemulsion a delivery system that can improve the bioavailability of UA and has great potential for sustained drug release and tumor targeting (Liao et al., 2019).

Miastkowska and Śliwa (2020) designed and successfully synthesized a UA nanoemulsion with a particle size of $248 \pm$ $15 \mathrm{~nm}$, but no tests related to biological activity have been conducted. Alvarado et al., successfully prepared a UAcontaining nanoemulsion, which exhibited strong proliferation inhibition against $\mathrm{B} 16$ melanoma cell lines (the $\mathrm{IC}_{50}$ was between 0.58 and $2.9 \mu \mathrm{M})$. Unfortunately, this nanoemulsion contains both UA and OA, and UA is not the only active drug. In the UA and OA nanoemulsion system, the average droplet diameter is approximately $198.95 \pm 21.34 \mathrm{~nm}$, with good stability and no obvious aggregation or deposition. In addition, in this study it was also observed that the emulsion prepared had a significant antioxidant effect, and the inhibition rate of 2,2-Diphenyl-1picrylhydrazyl (DPPH), a stable free radical, was approximately $88 \%$ (Alvarado et al., 2018). This may also be related to the oil phase of the emulsion being castor oil, in addition to the antioxidant capacity of UA itself, as castor oil has good antioxidant activity (Talukdar et al., 2019). These findings also demonstrate that nanometer emulsions have some advantages over other nanometer delivery systems.

\section{UA Nanoparticles}

Nanoparticles, including (organic) polymer nanoparticles and inorganic nanoparticles, are new drug carriers with great potential 
for development. The former are generally made using chitosan, polylactic acid, polycaprolactone, and other natural or synthetic polymers, while the latter are generally made using inorganic materials such as carbon, silicon dioxide, and bioceramics (Cheng L. et al., 2017). With respect to anti-tumor therapy, the nanoparticle drug-carrying system is conducive to the high concentration and continuous release of drugs and prolongs the retention time of drugs in the tumor, thereby improving the utilization rate of drugs, slowing tumor growth, and increasing anticancer efficacy (Majidzadeh et al., 2020).

\section{Chitosan Nanoparticles}

Chitosan is the only alkaline polysaccharide among natural polysaccharides. As a new nanosystem carrier, chitosan has good biocompatibility and biodegradability (Xia et al., 2018; Zhang Y. et al., 2019). UA has good ability to inhibit tumor angiogenesis, but its poor water solubility directly limits its effect.

Jin et al., successfully prepared a UA-loaded chitosan nanoparticle (CH-UA-NPS) with a drug loading rate of approximately $54 \%$ and a particle size of approximately $100 \mathrm{~nm}$. The results of both cell and animal experiments showed that $\mathrm{CH}-\mathrm{UA}-\mathrm{NPS}$ has a significant inhibitory effect on angiogenesis. Compared with free UA, the killing effect of nanoparticles on human umbilical vein endothelial cells was more obvious at the same concentration for $24 \mathrm{~h}\left(\mathrm{IC}_{50}: 82.5 \mathrm{vs}\right.$. $56.7 \mu \mathrm{g} / \mathrm{mL}$ ). In the mouse hepatocellular carcinoma model, no significant microangiogenesis was observed under the action of CH-UA-NPS; on the contrary, a high amount of tissue necrosis was observed. Cell necrosis may be related to the destruction of lysosomes and the mitochondrial membrane structure owing to $\mathrm{CH}-\mathrm{UA}-\mathrm{NPS}$ entering the cell. The inhibitory effect of $\mathrm{CH}-\mathrm{UA}-$ NPS on angiogenesis was also observed in a chick embryo chorioallantoic membrane model. Notably, CH-UA-NPS has also been shown to have a good anti-breast cancer effect. FA is a widely used targeting molecule (Jin et al., 2016b).

The successful synthesis of folate-targeting UA chitosan nanoparticles (FA-CS-UA-NPS) has been reported in a study (Jin et al., 2016a). Similar to the UA nanoparticles prepared by Jin et al., FA-CS-UA-NPS also damaged the membrane integrity of lysosomes and mitochondria when they entered the cell, thus inducing the death of cancer cells. The same study also showed that, within a certain range, the uptake of FA-CS-UA-NPS by cancer cells increased with increasing temperature, time, and dose. Cell tests showed that FA-CS-UA-NPS was more lethal than free UA against breast cancer MCF-7 cells. In order to observe the anti-breast cancer animal effect of FA-CS-UA-NPS, the researchers selected female MCF-7 tumor-bearing mice. After a randomized administration, the tumor weight was measured. The values of the FA-CS-UA-NPS, UA, and normal saline control groups were $2.1 \pm 1.02,3.48 \pm 0.24$, and $5.26 \pm 1.69$ g, respectively. These results indicated that the ability of FA-CS-UA-NPS to inhibit tumor growth is significant. In addition, experiments showed that FA-CS-UA-NPS may have an immuneboosting effect (superior to that of free UA) (Jin et al., 2016b).

\section{Polylactic Acid Nanoparticles}

Polylactic acid (PLA), a product of a certain amount of lactic acid condensation reaction, is a biodegradable polymer material with good biocompatibility and is an ideal carrier for drug-carrying nanoparticles (Wang $Z$ et al., 2020d). One study successfully prepared a UA polylactic acid nanoparticle with a high encapsulation rate of up to $96 \%$, which meant that the loss of UA was greatly reduced during the preparation process (Antônio et al., 2017). The cell test confirmed that UA polylactic acid nanoparticles had a certain killing ability against melanoma cells and were highly time-dependent. B16-F10 cell lines were observed under the action of different nanoparticle concentrations for $24 \mathrm{~h}$, and more than $80 \%$ of the cells survived; $48 \mathrm{~h}$ later, less than $40 \%$ of cells survived under high nanoparticle concentrations; $72 \mathrm{~h}$ later, the survival of cells was below 50\% under all nanoparticle concentrations. This is related to the in vivo release process of the nanoparticle, which has the ability of continuous slow release ( $72 \mathrm{~h} ; 45 \%$ release) after an initial sudden release ( $8 \mathrm{~h} ; 30 \%$ release). This suggests that by extending the observation cycle further, we may be able to observe more significant cellular lethality.

\section{Polycaprolactone Nanoparticles}

Polycaprolactone (PCL) is also a biodegradable polymer material that is chemically synthesized. Zhang et al., successfully prepared UA-containing polycaprolactone nanoparticles (UA-NPs) with an encapsulation rate of over $80 \%$. UA-NPs also exhibited a biphasic release similar to that of the aforementioned PLA nanoparticles, with UA release rates of approximately $28 \%$ within $8 \mathrm{~h}$. Both UA and UA-NPS can induce the death of $\mathrm{H} 22$ HCC cells, but the latter is more cytotoxic. The $\mathrm{IC}_{50}$ of $\mathrm{UA}$ and UA-NPS was $59.84 \pm 4.12$ and $32.89 \pm 3.23 \mu \mathrm{M}$, respectively. Compared with UA, UA-NPS exhibited stronger tumor suppressive ability in $\mathrm{H} 22$ transplanted mice treated with UA and UA-NPS. CT images of the mice showed that UA alleviated most tumor lesions, while the UA-NPS group was almost completely exhausted. Further studies demonstrated that this could be because UA and UA-NPS increased the expression of Bax and Caspase- 3 and decreased the expression of Bcl-2, while UA-NPS decreased the expression of Bcl-2 more clearly (Zhang et al., 2015).

\section{Poly (Lactic-co-glycolic Acid) Nanoparticles}

A Poly (lactic-co-glycolic acid) (PLGA) consists of the random polymerization of two monomers, lactic acid and glycolic acid. It is also a biodegradable functional polymer organic compound with good biocompatibility, good sac formation performance, and good membrane formation (Liu et al., 2020). One study confirmed that PLGA nanoparticles containing UA had a significant concentration-dependent cytotoxicity on B16-F10 mouse melanoma cell lines, with an $\mathrm{IC}_{50}$ of $18 \mu \mathrm{M}$ and a free $\mathrm{IC}_{50}$ of $60 \mu \mathrm{M}$. Similarly, the nanoparticles exhibited a biphasic release, and approximately $30 \%$ of UA was released within the first $4 \mathrm{~h}$ (Baishya et al., 2016). Studies have also shown that PLGA nanoparticles containing UA have good application prospects in the treatment of cervical cancer (Wang S. et al., 2017). One study confirmed that the prepared nanoparticles had good proliferation inhibition and significant apoptosis promotion effects on the three cervical cancer cell lines (SiHA, CaSki, and HeLa). Similar results have been reported in animal studies. This may be due to 
the high expression of P53, increased expression of caspase-3, caspase-8, and caspase-9, and decreased expression of Bcl-2 in cancer cells after nanoparticle treatment. In addition, PLGA nanoparticles containing UA have been shown to have potential therapeutic effects on human retinoblastoma (Silva et al., 2019). In one study, a mixture of UA and OA was used to prepare two kinds of nanoparticles, one loaded with a natural UA/OA mixture, and the other loaded with a synthetic UA/OA mixture. OA is an isomer of UA, which, like UA, belongs to the pentacyclic triterpenes and has significant anticancer properties (Cao et al., 2018). Both nanoparticles were stable (for at least 6 months) and were able to achieve an approximate $75 \%$ drug release within $72 \mathrm{~h}$. In this study, the researchers observed the cytotoxicity of the prepared nanoparticles on Y-79 cell lines. The results showed that both nanoparticles had significant cytotoxicity and were concentration-dependent. When treated with $32 \mathrm{umol} / \mathrm{L}$ of a natural UA/OA mixture of nanoparticles, approximately $87 \%$ of the Y-79 cell lines died.

\section{Mesoporous Silica Nanoparticles}

Nanoparticles prepared from materials such as chitosan, polylactic acid, and polycaprolactone are biodegradable nanoparticles (Souto et al., 2019). They may undergo hydrolysis or degradation reactions with environmental changes, which may increase unnecessary losses during transportation and ultimately affect the anti-cancer therapeutic effect of nanoparticles. However, Mesoporous silica nanoparticles (MSNs) can not only induce sustained drug release when loaded with more drug molecules, but also protect the drug from degradation by biological enzymes and reduce drug loss during transportation. In addition, studies have shown that the MSN surface is rich in silica hydroxyl, which is easy to modify and enables the design of different functional surfaces to meet different transport needs (Schmid et al., 2016).

The $\mathrm{pH}$-sensitive MSN drug delivery system is a common controlled release system in the MSN drug delivery system, which allows the drug to be released well in acidic tumor tissues. Li et al., successfully prepared $\mathrm{pH}$-sensitive MSNs containing UA. The release test results showed that the UA release rate at $\mathrm{pH} 5.5$ was higher than that at $\mathrm{pH} 7.4$ (60 vs. $40 \%$ ). In addition, the experiment showed that, compared with free UA, the MSNs infiltrated rapidly HepG2 cells, inhibited significantly the cell cycle, and promoted apoptosis (Li T. et al., 2017). The pHsensitive MSNs containing UA prepared by Zhao et al. (2017) also achieved good experimental results and showed good drug sustained-release effects. At the same time, they can inhibit the proliferation and migration of SMMC-7721 cells in liver cancer, promote the apoptosis of the cell line, and have significant hepatocellular toxicity. Zheng et al., designed UA-containing MSNs with FA targeting capability. In the study, the authors observed that MSNs showed significant sustained release under the same $\mathrm{pH}$ (7.4), and the release rate of UA was maintained at $75 \%$ after $48 \mathrm{~h}$. The high uptake of HeLa cells into the prepared nanoparticles was observed by fluorescence labeling. In addition, targeted modification has been shown to significantly improve the toxic effect of MSNs on HeLa cells with high FA expression (Zheng et al., 2017).

\section{UA Nanocrystals}

Nanocrystals (also known as nanocrystal suspensions or nanosuspensions) usually refer to the nanoscale dispersion system of pure drugs dispersed in liquid in crystalline or amorphous form, with a small amount of either a surfactant or polymer as a stabilizer (Teymouri Rad et al., 2017; Vora et al., 2018). Generally, nanocrystals do not use carriers, have few excipients, are simple to prepare, and have a high drug load. If the drug nanocrystals are controlled by particle size or modified by surface, they can also target specific parts, such as the liver, spleen, brain, or tumor tissues (Qin et al., 2018). In addition, studies have shown that nanocrystals can improve the uptake of insoluble drugs in Caco- 2 cells and the transmembrane transport rate (Di Costanzo and Angelico, 2019). These findings resulted in a new method to increase UA dissolution, improve UA bioavailability, and constitute the anticancer activity of UA more efficient.

In one study, UA nanocrystals with a particle size of approximately $188.0 \mathrm{~nm}$ were prepared successfully, with a dissolution rate of approximately $100 \%$ within $2 \mathrm{~h}$ in $0.5 \%$ sodium dodecyl sulfate solution. Subsequent experiments showed that UA nanocrystals had concentration-time dependent cytotoxic effects on MCF-7 cell lines of breast cancer, with an $\mathrm{IC}_{50}$ value of approximately half that of free UA. Generally speaking, the smaller the nanocrystal particle size, the faster the drug is dissolved, and thus, better absorption may be achieved. However, the particle size and distribution of the drug in nanocrystals change constantly when the drug is put to rest. The results of the aforementioned study showed that the diameter of the UA nanosuspensions increased to $199.5 \mathrm{~nm}$ after 49 days at $4^{\circ} \mathrm{C}$. In order to keep the particles in the suspension stable and prevent agglomeration or settlement, it is necessary to add a proper stabilizer to the suspension. However, it should be mentioned that the nanocrystalline was prepared without a stabilizer, and the desired stability was obtained nonetheless. The specific principle needs to be studied further. It is worth noting that the stability may be temporary, because the polymer dispersion coefficient value also increases to a certain extent as the grain size increases to $199.5 \mathrm{~nm}$ (Song et al., 2014). Pi et al., used poloxamer 188 as a stabilizer and prepared short bar-shaped UA nanocrystals with an average particle size of $291.7 \mathrm{~nm}$ and barshaped UA microcrystalline with an average particle size of $1,299.3 \mathrm{~nm}$ using the high-pressure homogenization method. Compared with the ordinary UA suspension, the dissolution rate of nanocrystals was better and the bioavailability of nanocrystals was 2.56 times higher (that of microcrystalline was only 1.40 times higher) (Pi et al., 2016). Wang et al. (2015) evaluated the effect of UA nanocrystals with different particle sizes on the proliferative activity of MCF-7 breast cancer cells in vitro. The results showed that both early and late apoptotic rates were significantly higher for nanocrystals with a particle size of $300 \mathrm{~nm}$ than for those with a particle size of $100 \mathrm{~nm}$. This may be related to the change in adhesion, which increases the contact time with cells and promotes the phagocytosis of particles by cells. However, a small particle size is generally more conducive to dissolution, so there may be a nanocrystal size with the best efficacy. 


\section{Carrier-Free Nanoformulations Containing Indocyanine Green, a Photosensitizer}

Indocyanine green (ICG) is a clinical near-infrared light (NIR) fluorescent dye with excellent biocompatibility and approved by the FDA. It has been applied in many fields, such as the imaging diagnosis of diseases and photothermal therapy (Chen T. et al., 2018; Li C. et al., 2020). Nanoparticles loaded with ICG, UA or other chemotherapy drugs can promote the efficient release of chemotherapy drugs and, at the same time, achieve accurate localization of the lesion, which has great application potential for the diagnosis of tumor diseases.

Guo et al., combined UA, PTX, and ICG into a carrier-free spherical nanoparticle (ICG @ UA/PTX NPs) with a particle size of approximately $130.8 \mathrm{~nm}$ and good stability, even if stored in an aqueous solution for 20 days. This may be due to the electrostatic and hydrophobic interactions between the co-assembled nanoparticles. After $5 \mathrm{~min}$ of NIR laser irradiation, the temperature of the NPs increased from 39 to $65^{\circ} \mathrm{C}$. The cell test showed that, compared with NIR-free cells, the nanoparticles had more significant cytotoxicity on HepG2 cancer cells and HeLa cells under the action of NIR laser. The H22 tumor-bearing mouse model was used in the animal experiments. The results showed that the tumor volume of mice exposed to NIR nanoparticles decreased significantly compared with that of other groups, and there was no tumor recurrence during the 21-days observation period. Although the study showed that a large number of ICG @ UA/PTX NPs were endocytosed by HepG2 cancer cells within $3 \mathrm{~h}$, in another study, the prepared nanoparticles were added with hepatotargeting LA molecules. Finally, the nanoparticles UA-LA-ICG NPs were prepared, making the intracellular fluorescence intensity stronger (Zhao et al., 2018). The death rate of HepG2 cells was $95 \%$, and the tumor inhibition rate of the $\mathrm{H} 22$ tumor-bearing mouse model was $96.32 \%$. Notably, neither nanoparticle was observed to have tumor recurrence in the mouse model and did not cause major organ damage in the mice (Guo et al., 2017).

\section{Self-Assembled Nanoformulations Combined With Chemotherapeutic Agents}

The UA nanoformulations, combined with chemotherapeutic agents, allows for more precise release of cargo to its destination. And depending on the design, it can be released simultaneously or sequentially during transmission, creating synergies and enhancing therapeutic effects. UA was chemically conjugated to low molecular weight heparin (LMWH) to produce micellar LMWH-UA, which improves the efficacy of LMWH against tumor angiogenesis and reduces the risk of bleeding in cancer therapy. Experimental observations have demonstrated that LMWH-UA successfully reduces the risk of bleeding by reducing the affinity of antithrombin. The degradation of LMWH-UA in the plasma was $6.64 \pm 0.87 \%$ after $72 \mathrm{~h}$, indicating that LMWH-UA has good stability in the plasma. LMWH-UA shows high affinity to mouse melanoma B16F10 cells through specific polypeptidemediated endocytosis (Cheng W. et al., 2017).

Furthermore, UA is a natural molecule with self-assembly properties, which can combine with other chemical molecules to form supramolecular compounds with specific structures and properties (Lu et al., 2019; Grosu et al., 2020). Paclitaxel (PTX) is one of the chemotherapeutic drugs widely used in clinic. Wang et al., prepared nanoparticles UA-PTX by means of intermolecular hydrogen bonding and hydrophobic interaction through self-assembly, which had good stability and could be rapidly absorbed by tumor cells, and basically realized complete drug loading under the coordination of intermolecular forces without showing the phenomenon of explosive release. This was confirmed by subsequent experimental observations. The half-life of UA-PTX nanoparticles was significantly longer in vivo, about six times that of PTX alone. In addition, UA and PTX were observed to block MCF-7 tumor cell proliferation and induce apoptosis through different mechanisms, respectively, both of which had synergistic anti-tumor effect and reached a tumor inhibition rate of $90 \%$ (Wang et al., 2020b).

\section{CLINICAL STUDIES OF UA NANOFORMULATIONS}

Clinical study is a systematic study of a drug in humans (patients or healthy volunteers) with the purpose of determining the efficacy and safety of the drug under test (De Rycker et al., 2018). Although the good anticancer effect of UA nanoformulations has been confirmed in cell or animal preclinical experiments, clinical studies on UA nanoformulations are still insufficient and need to be further explored. Xia et al. enrolled 8 healthy volunteers in a single-dose study of ursolic acid liposomes $\left(98 \mathrm{mg} / \mathrm{m}^{2}\right)$ in 2010 , however, only a few pharmacokinetic parameters were observed to demonstrate the success of the new detection methods. The values of maximum plasma concentration $\left(C_{\max }\right)$, time to maximum plasma concentration $\left(T_{\max }\right)$, half-life $\left(t_{1 / 2}\right)$, area under the plasma concentration time curve $\left(\mathrm{AUC}_{0 \rightarrow \mathrm{t}}\right)$, and AUC $_{0 \rightarrow \infty}$, were $3,404.6 \pm 748.8 \mathrm{ng} / \mathrm{mL}, 4.0 \pm 0.0 \mathrm{~h}, 3.9 \pm$ $2.1 \mathrm{~h}, 9,644.1 \pm 1,193.2 \mathrm{ng} \mathrm{h} / \mathrm{mL}, 9,918.4 \pm 1,215.2 \mathrm{ngh} / \mathrm{mL}$, respectively (Xia et al., 2011). Zhu et al. enrolled 24 healthy volunteers and 8 tumor patients in the single-dose PK study and the multiple-dose PK study, respectively. Twenty-four volunteers in the single-dose study were randomly assigned to 37,74 , and $98 \mathrm{mg} / \mathrm{m}^{2}$ doses, while eight patients in the multiple-dose study received $74 \mathrm{mg} / \mathrm{m} 2$ doses for 14 consecutive days. The $C_{\max }$ and $\mathrm{AUC}_{0 \rightarrow 16 \mathrm{~h}}$ increased linearly with dose escalation. But in the multiple-dose study, The $C_{\max }, T_{\max }$ and $\mathrm{t} 1 / 2$ on the first day was similar to those on the 14th day $\left(C_{\max } 1,589 \pm 635\right.$ vs. $1,211 \pm$ $204 \mathrm{ng} / \mathrm{mL}, T_{\max } 3.00 \pm 1.41$ vs. $3.63 \pm 1.06 \mathrm{~h}$, and $\mathrm{t}_{1 / 2} 4.58 \pm$ 2.04 vs. $4.00 \pm 1.27 \mathrm{~h}$ ), indicating to some extent that no drug accumulation was observed after repeated administration. In the whole study, UA liposom-related adverse events were mostly mild to moderate, and the common adverse reactions were nausea, diarrhea and abdominal distension, indicating that UA liposomes were well tolerated (Zhu et al., 2013). Wang et al. enrolled 63 subjects for a single-dose study of UA liposomes, which also presented linear values of pharmacokinetic parameters. Moreover, this study showed that the maximum tolerated dose of UA liposomes was $98 \mathrm{mg} / \mathrm{m}^{2}$ (Wang et al., 
2013). In 2015, Qian et al. conducted a phase I clinical trial with 21 participants to evaluate the efficacy and tolerability of UA liposomes. The trial observed that about $60 \%$ of patients stabilized after two cycles of treatment, and indicated that UA liposomes did not accumulate in vivo. Furthermore, this trial concluded that the recommended dose of UA liposomes was $98 \mathrm{mg} / \mathrm{m}^{2}$, of course, which would need to be confirmed by a phase II clinical trial (Qian et al., 2015).

\section{CURRENT SITUATION AND FUTURE PROSPECTS OF UA NANOFORMULATIONS}

\section{Current Situation}

The research of natural molecule UA in the nanofield has made great progress. Through extensive inquiry and research, we have summarized the main antitumor research achievements of current UA nanoformulations in Table 2, and have illustrated the process from preparation to anticancer effect of UA nanoformulations by taking double-responsive liposomes as an example in Figure 4. The improvement of the antitumor ability of the UA nanoformulations is mainly due to the improvement of the bioavailability and the enhancement of the targeting ability of the UA molecules. First of all, bioavailability is the rate and extent to which a drug is absorbed into the circulation of the body, which is affected by the chemical structure, solubility, hydrophilic lipophilicity, stability, dosage form characteristics and other factors of the drug molecule (Tjandrawinata et al., 2018). The stability, surface modification and the development of preparation technology of nanoformulations have greatly improved the bioactivity and bioavailability of UA molecules (Yang et al., 2012; Antonio et al., 2021). Studies have confirmed that the area under the plasma drug concentration-time curve (AUC) and the peak concentration $\left(C_{\max }\right)$ that can be achieved after administration of UA nanoformulations in vivo are 2-3 times that of the original UA molecules (Pi et al., 2016; Qiu et al., 2019). Moreover, EPR effect is the basic principle of passive targeting of nanoformulations to tumor tissues. However, due to the complex internal environmental changes in organisms, it is not sufficient to rely solely on EPR effect, so molecular modification is usually carried out on the surface of nanoparticles, such as FA and lactose acid. Modified molecules act as ligands to enhance the targeting activity of nanoformulations and endocytosis of tumor cells by interacting with tumor cell surface receptors. With the help of fluorescence imaging technology, it has been proved that modified UA nanoparticles are more easily distributed in tumor tissues and display strong fluorescence images (Jin et al., 2016a; Zhao et al., 2018). Finally, UA combined with other chemotherapy drugs or other natural anticancer molecules has synergistic therapeutic effects, which may be a good method for the treatment of drug resistance of cancer, because experiments have proved that combined therapy can induce apoptosis of cancer cells through different signaling pathways and reduce the use of chemotherapeutic drugs (Alvarado et al., 2018; Silva et al., 2019; Sun S. et al., 2020).
Currently, the design of UA nanoformulations is very diverse according to the purpose, whether to increase the stability of drug circulation, or to release drugs slowly and effectively, reduce the accumulation of non-targeted sites. On a certain extent, they all aimed to increase the efficacy of UA and promotes its better clinical application. Liposomes are basically perfect systems with components similar to biofilm compositions and are designed to move drug molecules across specific cell membranes, offering excellent drug delivery potential (Lee, 2020). However, due to the fluidity similar to that of biofilms, liposomes are easily affected by temperature changes in vivo, resulting in membrane permeability changes and drug leakage. Micelle has a unique cored-shell structure, but compared with other common types of nanomaterials, the drug loading of micelle is usually less, which may make it difficult to exert the expected therapeutic effect of UA (Siboro et al., 2020). Nanocrystals is pure drug nano preparation with a very perfect drug loading capacity, and is easy to scale up production. Moreover, nanocrystals have a wide range of applications, including transdermal, ocular, nasal, and lung drug delivery. The same is true of nanoemulsion. Nevertheless, nanoemulsion system is relatively fragile, and may be out of balance even with small changes in the environment (Jarvis et al., 2019; Naseema et al., 2021).

Also, PCL, PLA, PLGA, MSNs, chitosan, and other materials are commonly used as nano-delivery carriers for UA nanoformulations. Safety is an important driving force for the use of nanocarriers as pharmaceutical excipients. After the drug has been delivered to the site, the carrier material itself should be completely excreted within a reasonable period of time, or its metabolites should be clear and non-toxic. Chitosan is a natural cationic polysaccharide, which can make drugs enter cells by interacting with negatively charged residues in membrane proteins (Torres-Rosas et al., 2020). PLA is a kind of renewable biodegradable material derived from starch production, which eventually generates carbon dioxide and water and realizes the circulation in nature. PLA is an ideal green polymer material. PCL, which is the same as PLA metabolites, is also favored due to its excellent biocompatibility and biodegradability. It has good flexibility and processability, and is easy to form film, although its mechanical strength is slightly insufficient (Zhai et al., 2017; Brčić et al., 2021). PLGA is formed by the polymerization of two kinds of monomers including PLA. Its performance is related to the proportion of monomers. The lower the proportion of PLA, the easier the degradation of PLGA. PLGA has good biocompatibility and has been certified as a safe medical excipient (Houshmand et al., 2020). Different from PCL, PLA, PLGA and other polymer materials, MSNs is an inorganic material, which is hard to be degraded by biological enzymes in the body, so it can reduce the drug loss in the delivery process. And it is convenient for surface functional modification. Significantly, the stability of the nanoparticle circulation in vivo was enhanced after the encapsulation of the carrier. However, the carrier occupies a large proportion in the whole nanosystem, which affects the drug loading efficiency of nanoformulations (Wang et al., 2020a). Therefore, the nanosystem assembled without carrier emerges as the times 


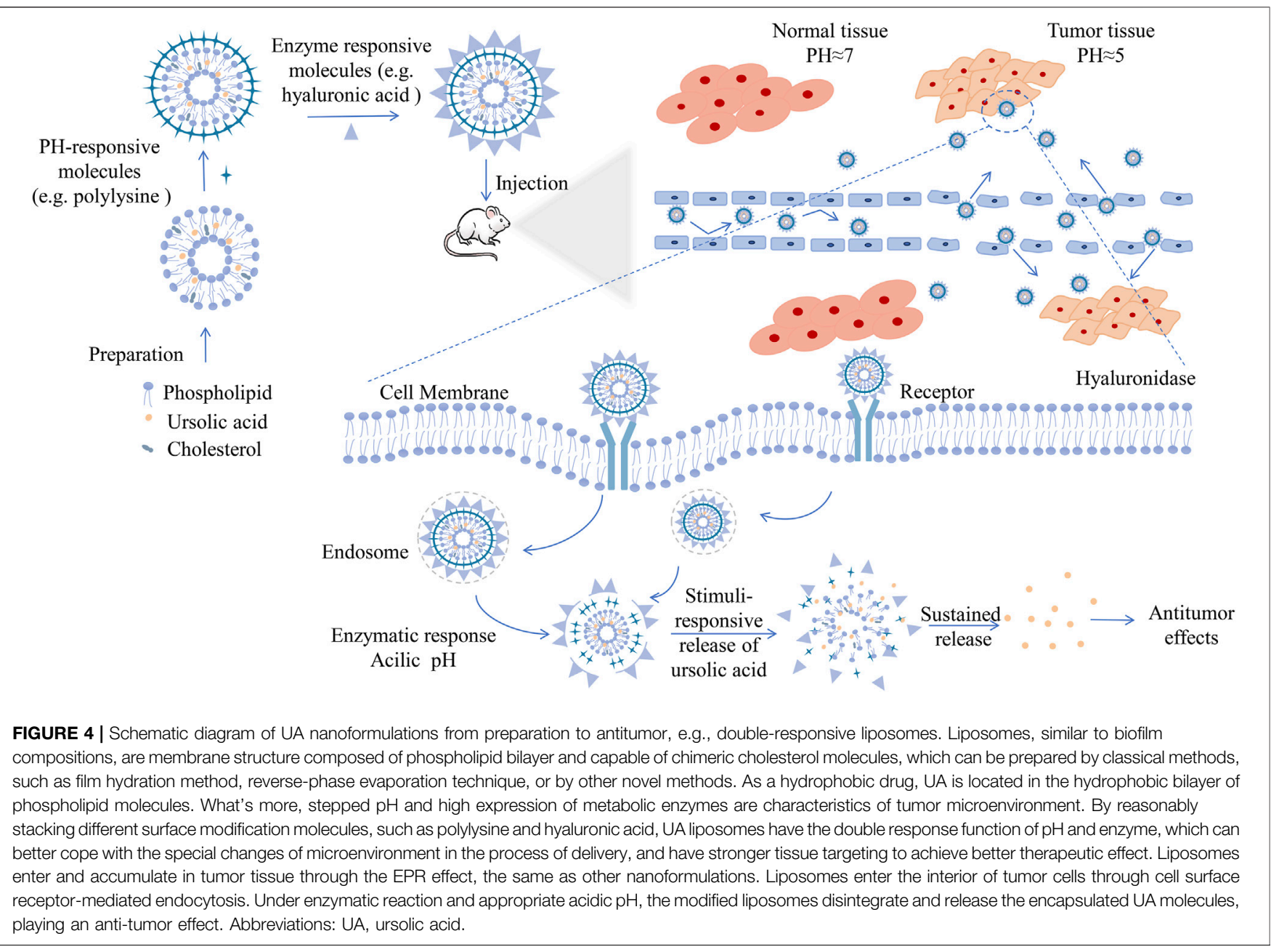

require, and it can combine with photosensitizer to play an excellent image diagnosis and optical treatment effect.

\section{Future Prospects}

Although research on UA nanoformulations has progressed adequately, there are still some problems to be solved. The ideal nanoformulations should be able to penetrate the core of a tumor tissue at a high drug concentration, enter the tumor cells where the target molecules are located, completely eradicate the tumor, and improve the survival rate of patients. This involves five steps: entering the blood circulation, enriching the tumor site, infiltrating the tumor tissue, reaching the tumor cells, and being ingested by them. Finally, the drug is released inside the cell (Dong et al., 2019). Tumor tissue penetration is an indispensable and important link for the efficacy of nanoformulations (Wadajkar et al., 2019).

The permeability of nanoformulations is related to the heterogeneity of the tumor microenvironment (Feng and Mumper, 2013; Vong and Nagasaki, 2020). Nanoformulations' diffusion is also limited by the pressure of the interstitial fluid in the tumor microenvironment after passing through the tumor neovascularization wall from the basement membrane defect.
Although nanoformulations can respond to changes in $\mathrm{pH}$ or enzymes in the microenvironment with a single or multifunctional modification, the permeability can be improved to a certain extent; however, studies have shown that this improvement is inefficient. This may be because the large size of the nanoformulations makes it difficult to move around in complex microenvironments compared to small molecules. Nanopreparation modifications have not progressed greatly. Therefore, is it feasible to reduce the pressure of the tumor microenvironment intermediate fluid? The answer is no. Owing to changes in the interstitial fluid in the microenvironment, cancer cells may be more susceptible to invasion and metastasis, which to some extent defeats the purpose of cancer treatment. A significant step forward and a potential answer to this dilemma, may be the findings of certain studies that have shown that adenosine triphosphate, which plays an important role in various physiological activities of cells, can act as a stimulant to control drug release in some tumor tissues. Thus, to some extent, the permeability of nanoformulations in tumor tissue active transport may be improved by the way of active transport based on the energy consumption of adenosine triphosphate (Moradi Kashkooli et al., 2020; Zhou et al., 2020). 


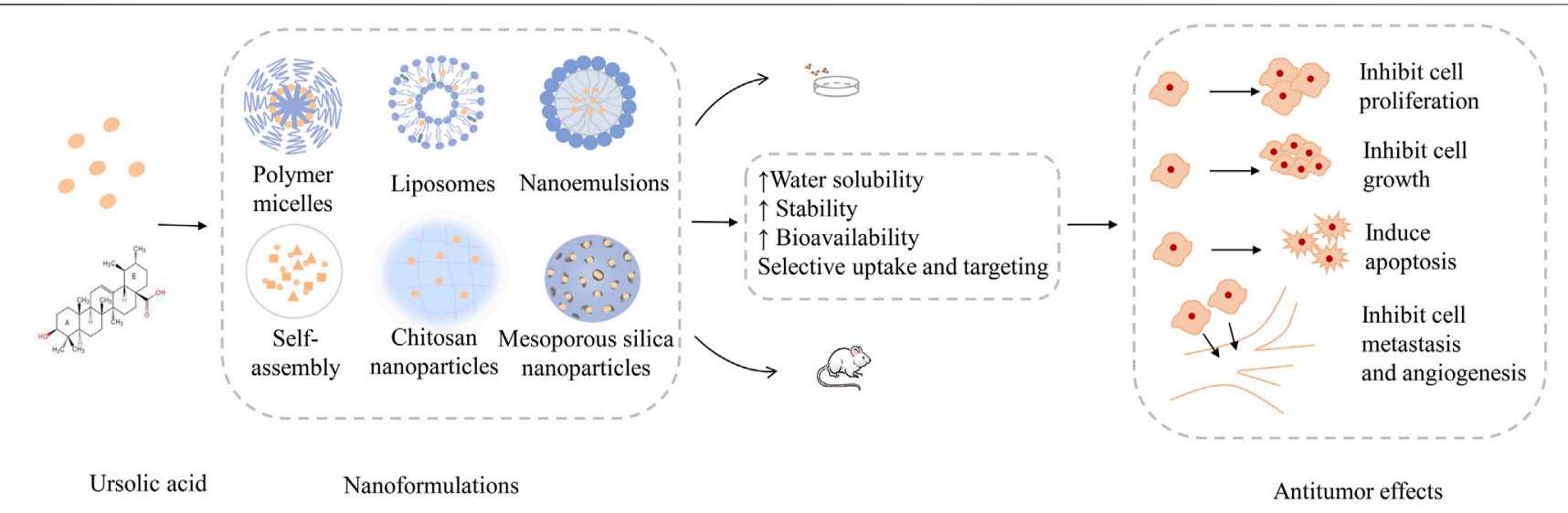

FIGURE 5 | The main properties of UA nanoformulations and their therapeutic efficacy. UA nanoformulations are designed in a variety of ways, such as, polymer micelles, liposomes, nanoemulsions, nanoparticles, etc. Confirmed by a large number of cell and animal experiments, the UA nanoformulations can improve the water solubility, stability, bioavailability and tissue targeting of UA molecules, and achieve good anti-tumor effect by inhibiting the growth, proliferation and metastasis of tumor cells, promoting tumor cell apoptosis and inhibiting tumor angiogenesis. Abbreviations: UA, ursolic acid.

As research progresses, the delivery efficiency of UA nanoformulations may be improved significantly; however, there is still a long way to go before clinical application. To date, the physicochemical properties and metabolic behavior of UA nanopreparations in vivo have not been fully elucidated, so indepth preclinical experimental and clinical trial explorations are necessary. Establishing large animal models of various cancer types, or combining mathematical models to simulate and track the in vivo behavior of UA nanoformulations may be beneficial to further evaluate their in vivo characteristics (He et al., 2020). Another important indicator of the clinical application of UA nanoformulations is the quantification of production (Feng et al., 2019). At present, promoting the efficient transportation of nanoformulations is achieved mainly by gathering different functional groups into the same polymer, which increases the complexity of nanoformulations' structure and further reduces the controllability of their large-scale production. Ideally, a modified nanoparticle with one group would complete the entire delivery process, which would be a good clinical transformation.

\section{CONCLUSION}

This review highlighted the advantages and disadvantages of UA as a natural plant-based anticancer compound, indicating that new cancer treatment strategies based on nanotechnology for UA have broad clinical application prospects. The mature application

\section{REFERENCES}

Alvarado, H. L., Calpena, A. C., Garduño-Ramírez, M. L., Ortiz, R., Melguizo, C., Prados, J. C., et al. (2018). Nanoemulsion Strategy for Ursolic and Oleanic Acids Isolates from Plumeria Obtusa Improves Antioxidant and Cytotoxic Activity in Melanoma Cells. Acamc 18, 847-853. doi:10.2174/1871520618666180111151846 Antônio, E., Antunes, O. d. R., de Araújo, I. S., Khalil, N. M., and Mainardes, R. M. (2017). Poly(lactic Acid) Nanoparticles Loaded with Ursolic Acid: of nanotechnology in the field of medicine has smoothed the path of cancer treatment. Based on the EPR effect, nanoformulations selectively concentrate in tumor tissues and reduce the distribution of normal tissues, which, to some extent, enhances the anticancer efficacy of drugs and reduces drug-induced adverse reactions. Currently, a variety of UA nanoformulations, such as micelles, liposomes, nanoparticles, and nanocrystals, which have higher stability, better absorption rates, and higher cancer cell lethality than UA compounds, have been prepared successully. The main properties of UA nanoformulations and their therapeutic efficacy are shown in Figure 5. Despite the current research on the nanoformulations is still in the laboratory stage, with the continuous thinking and hard exploration of the vast number of researchers and engineers, a stable, efficient, safe and industrially reproducible ideal UA nanoformulations is worth looking forward to.

\section{AUTHOR CONTRIBUTIONS}

The research project was designed by LW, QY, CS, and JZ. LW collected the literature, drew structures; LW and QY wrote the manuscript and checked the Tables and Figures as well as grammar of manuscript. CL and YT revised the manuscript. CS and JZ participated in and helped draft the manuscript. All authors have read and approved the final version of the manuscript.

Characterization and In Vitro Evaluation of Radical Scavenging Activity and Cytotoxicity. Mater. Sci. Eng. C 71, 156-166. doi:10.1016/ j.msec.2016.09.080

Antonio, E., Dos Reis Antunes Junior, O., Marcano, R. G. D. J. V., Diedrich, C., Da Silva Santos, J., Machado, C. S., et al. (2021). Chitosan Modified Poly (Lactic Acid) Nanoparticles Increased the Ursolic Acid Oral Bioavailability. Int. J. Biol. Macromol. 172, 133-142. doi:10.1016/j.ijbiomac.2021.01.041

Baishya, R., Nayak, D. K., Kumar, D., Sinha, S., Gupta, A., Ganguly, S., et al. (2016). Ursolic Acid Loaded PLGA Nanoparticles: In Vitro and In Vivo Evaluation to 
Explore Tumor Targeting Ability on B16F10 Melanoma Cell Lines. Pharm. Res. 33, 2691-2703. doi:10.1007/s11095-016-1994-1

Brčić, M., Kršćanski, S., and Brnić, J. (2021). Rotating Bending Fatigue Analysis of Printed Specimens from Assorted Polymer Materials. Polymers (Basel) 13, 1020. doi:10.3390/polym13071020

Calcabrini, C., Catanzaro, E., Bishayee, A., Turrini, E., and Fimognari, C. (2017). Marine Sponge Natural Products with Anticancer Potential: An Updated Review. Mar. Drugs 15, 310. doi:10.3390/md15100310

Caldeira de Araújo Lopes, S., Vinícius Melo Novais, M., Salviano Teixeira, C., Honorato-Sampaio, K., Tadeu Pereira, M., Ferreira, L. A. M., et al. (2013). Preparation, Physicochemical Characterization, and Cell Viability Evaluation of Long-Circulating and pH-Sensitive Liposomes Containing Ursolic Acid. Biomed. Research International 2013, 1-7. doi:10.1155/2013/467147

Cao, S., Tian, X.-L., Yu, W.-X., Zhou, L.-P., Dong, X.-L., Favus, M. J., et al. (2018). Oleanolic Acid and Ursolic Acid Improve Bone Properties and Calcium Balance and Modulate Vitamin D Metabolism in Aged Female Rats. Front. Pharmacol. 9, 1435. doi:10.3389/fphar.2018.01435

Cargnin, S. T., and Gnoatto, S. B. (2017). Ursolic Acid from Apple Pomace and Traditional Plants: A Valuable Triterpenoid with Functional Properties. Food Chem. 220, 477-489. doi:10.1016/j.foodchem.2016.10.029

Castrejón-Jiménez, N. S., Leyva-Paredes, K., Baltierra-Uribe, S. L., Castillo-Cruz, J., Campillo-Navarro, M., Hernández-Pérez, A. D., et al. (2019). Ursolic and Oleanolic Acids Induce Mitophagy in A549 Human Lung Cancer Cells. Molecules, 24, 3444. doi:10.3390/molecules24193444

Chen, C.-J., Shih, Y.-L., Yeh, M.-Y., Liao, N.-C., Chung, H.-Y., Liu, K.-L., et al. (2019). Ursolic Acid Induces Apoptotic Cell Death through AIF and Endo G Release through a Mitochondria-dependent Pathway in NCI-H292 Human Lung Cancer Cells In Vitro. In Vivo (Athens, Greece) 33, 383-391. doi:10.21873/ invivo. 11485

Chen, Q., Luo, S., Zhang, Y., and Chen, Z. (2011). Development of a Liquid Chromatography-Mass Spectrometry Method for the Determination of Ursolic Acid in Rat Plasma and Tissue: Application to the Pharmacokinetic and Tissue Distribution Study. Anal. Bioanal. Chem. 399, 2877-2884. doi:10.1007/s00216011-4651-x

Chen, T., Ren, L., Liu, X., Zhou, M., Li, L., Xu, J., et al. (2018). DNA Nanotechnology for Cancer Diagnosis and Therapy. Int. J. Mol. Sci. 19, 1671. doi:10.3390/ijms19061671

Chen X., X., Zhu, P., Liu, B., Wei, L., and Xu, Y. (2018). Simultaneous Determination of Fourteen Compounds of Hedyotis Diffusa Willd Extract in Rats by UHPLC-MS/MS Method: Application to Pharmacokinetics and Tissue Distribution Study. J. Pharm. Biomed. Anal. 159, 490-512. doi:10.1016/ j.jpba.2018.07.023

Chen, Y., Sun, J., Lu, Y., Tao, C., Huang, J., Zhang, H., et al. (2013). Complexes Containing Cationic and Anionic $\mathrm{pH}$-Sensitive Liposomes: Comparative Study of Factors Influencing Plasmid DNA Gene Delivery to Tumors. Int. J. Nanomedicine 8, 1573-1593. doi:10.2147/ijn.S42800

Chen, Y.-C., Lo, C.-L., and Hsiue, G.-H. (2014). Multifunctional Nanomicellar Systems for Delivering Anticancer Drugs. J. Biomed. Mater. Res. 102, 2024-2038. doi:10.1002/jbm.a.34850

Chen, Y.-M., Tang, B.-X., Chen, W.-Y., and Zhao, M.-S. (2020). Ursolic Acid Inhibits the Invasiveness of A498 Cells via NLRP3 Inflammasome Activation. Oncol. Lett. 20, 1. doi:10.3892/ol.2020.12027

Cheng, L., Jiang, D., Kamkaew, A., Valdovinos, H. F., Im, H.-J., Feng, L., et al. (2017). Renal-Clearable PEGylated Porphyrin Nanoparticles for Image-Guided Photodynamic Cancer Therapy. Adv. Funct. Mater. 27, 1702928. doi:10.1002/ adfm.201702928

Cheng, W., Dahmani, F. Z., Zhang, J., Xiong, H., Wu, Y., Yin, L., et al. (2017). Antiangiogenic Activity and Antitumor Efficacy of Amphiphilic Twin Drug from Ursolic Acid and Low Molecular Weight Heparin. Nanotechnology 28, 075102. doi:10.1088/1361-6528/aa53c6

Choudhari, A. S., Mandave, P. C., Deshpande, M., Ranjekar, P., and Prakash, O. (2019). Phytochemicals in Cancer Treatment: From Preclinical Studies to Clinical Practice. Front. Pharmacol. 10, 1614. doi:10.3389/ fphar.2019.01614

Chung, T.-W., Choi, H., Lee, J.-M., Ha, S.-H., Kwak, C.-H., Abekura, F., et al. (2017). Oldenlandia Diffusa Suppresses Metastatic Potential through Inhibiting Matrix Metalloproteinase-9 and Intercellular Adhesion Molecule-1 Expression via P38 and ERK1/2 MAPK Pathways and Induces Apoptosis in Human Breast
Cancer MCF-7 Cells. J. ethnopharmacology 195, 309-317. doi:10.1016/ j.jep.2016.11.036

Cuevas-Flores, M. d. R., Bartolomei, M., García-Revilla, M. A., and Coletti, C. (2020). Interaction and Reactivity of Cisplatin Physisorbed on Graphene Oxide Nano-Prototypes. Nanomaterials, 10, 1074. doi:10.3390/nano10061074

De Angel, R. E., Smith, S. M., Glickman, R. D., Perkins, S. N., and Hursting, S. D. (2010). Antitumor Effects of Ursolic Acid in a Mouse Model of Postmenopausal Breast Cancer. Nutr. Cancer 62, 1074-1086. doi:10.1080/01635581.2010.492092

De Rycker, M., Baragaña, B., Duce, S. L., and Gilbert, I. H. (2018). Challenges and Recent Progress in Drug Discovery for Tropical Diseases. Nature 559, 498-506. doi:10.1038/s41586-018-0327-4

Di Costanzo, A., and Angelico, R. (2019). Formulation Strategies for Enhancing the Bioavailability of Silymarin: The State of the Art. Molecules 24, 2155. doi:10.3390/molecules24112155

Dong, H., Pang, L., Cong, H., Shen, Y., and Yu, B. (2019). Application and Design of Esterase-Responsive Nanoparticles for Cancer Therapy. Drug Deliv. 26, 416-432. doi:10.1080/10717544.2019.1588424

Du, Y., and Chen, B. (2019). Combination of Drugs and Carriers in Drug Delivery Technology and its Development. Dddt 13, 1401-1408. doi:10.2147/ dddt.S198056

Dwivedi, G. R., Maurya, A., Yadav, D. K., Khan, F., Darokar, M. P., and Srivastava, S. K. (2015). Drug Resistance Reversal Potential of Ursolic Acid Derivatives against Nalidixic Acid- and Multidrug-resistant Escherichia Coli. Chem. Biol. Drug Des. 86, 272-283. doi:10.1111/cbdd.12491

Dwivedi, G. R., Maurya, A., Yadav, D. K., Khan, F., Gupta, M. K., Gupta, P., et al. (2019). Comparative Drug Resistance Reversal Potential of Natural Glycosides: Potential of Synergy Niaziridin \& Niazirin. Ctmc 19, 847-860. doi:10.2174/ 1568026619666190412120008

Feng, J., Markwalter, C. E., Tian, C., Armstrong, M., and Prud'homme, R. K. (2019). Translational Formulation of Nanoparticle Therapeutics from Laboratory Discovery to Clinical Scale. J. Transl Med. 17, 200. doi:10.1186/ s12967-019-1945-9

Feng, L., and Mumper, R. J. (2013). A Critical Review of Lipid-Based Nanoparticles for Taxane Delivery. Cancer Lett. 334, 157-175. doi:10.1016/ j.canlet.2012.07.006

Ghadiri, M., Young, P., and Traini, D. (2019). Strategies to Enhance Drug Absorption via Nasal and Pulmonary Routes. Pharmaceutics 11, 113. doi:10.3390/pharmaceutics11030113

Gou, W., Luo, N., Wei, H., Wu, H., Yu, X., Duan, Y., et al. (2020a). Ursolic Acid Derivative UA232 Evokes Apoptosis of Lung Cancer Cells Induced by Endoplasmic Reticulum Stress. Pharm. Biol. 58, 707-715. doi:10.1080/ 13880209.2020 .1794013

Grosu, I. G., Filip, X., Miclău $\square$, M. O., and Filip, C. (2020). Hydrogen-Mediated Noncovalent Interactions in Solids: What Can NMR Crystallography Tell about?. Molecules 25, 3757. doi:10.3390/molecules 25163757

Gu, W., Jin, X.-Y., Li, D.-D., Wang, S.-F., Tao, X.-B., and Chen, H. (2017). Design, Synthesis and In Vitro Anticancer Activity of Novel Quinoline and Oxadiazole Derivatives of Ursolic Acid. Bioorg. Med. Chem. Lett. 27, 4128-4132. doi:10.1016/j.bmcl.2017.07.033

Guo, W., Xu, B., Wang, X., Zheng, B., Du, J., and Liu, S. (2020b). The Analysis of the Anti-tumor Mechanism of Ursolic Acid Using Connectively Map Approach in Breast Cancer Cells Line MCF-7. Cmar 12, 3469-3476. doi:10.2147/ cmar.S241957

Guo, Y., Jiang, K., Shen, Z., Zheng, G., Fan, L., Zhao, R., et al. (2017). A Small Molecule Nanodrug by Self-Assembly of Dual Anticancer Drugs and Photosensitizer for Synergistic Near-Infrared Cancer Theranostics. ACS Appl. Mater. Inter. 9, 43508-43519. doi:10.1021/acsami.7b14755

Hao, W., Kwek, E., He, Z., Zhu, H., Liu, J., Zhao, Y., et al. (2020). Ursolic Acid Alleviates Hypercholesterolemia and Modulates the Gut Microbiota in Hamsters. Food Funct. 11, 6091-6103. doi:10.1039/d0fo00829j

He, B., Sui, X., Yu, B., Wang, S., Shen, Y., and Cong, H. (2020). Recent Advances in Drug Delivery Systems for Enhancing Drug Penetration into Tumors. Drug Deliv. 27, 1474-1490. doi:10.1080/10717544.2020.1831106

He, W., Shi, F., Zhou, Z., Li, B., Zhang, K., Zhang, X., et al. (2015). A Bioinformatic and Mechanistic Study Elicits the Antifibrotic Effect of Ursolic Acid through the Attenuation of Oxidative Stress with the Involvement of ERK, PI3K/Akt, and P38 MAPK Signaling Pathways in Human Hepatic Stellate Cells and Rat Liver. Drug Des. Dev. Ther. 9, 3989-4104. doi:10.2147/dddt.S85426 
Houshmand, M., Garello, F., Circosta, P., Stefania, R., Aime, S., Saglio, G., et al. (2020). Nanocarriers as Magic Bullets in the Treatment of Leukemia. Nanomaterials 10, 276. doi:10.3390/nano10020276

Hu, Y., Gong, X., Zhang, J., Chen, F., Fu, C., Li, P., et al. (2016). Activated ChargeReversal Polymeric Nano-System: The Promising Strategy in Drug Delivery for Cancer Therapy. Polymers 8, 99. doi:10.3390/polym8040099

Hua, W. J., Fang, H. J., and Hua, W. X. (2012). Transepithelial Transport of Rosuvastatin and Effect of Ursolic Acid on its Transport in Caco-2 Monolayers. Eur. J. Drug Metab. Pharmacokinet. 37, 225-231. doi:10.1007/s13318-0120094-9

Ikeda, Y., Murakami, A., and Ohigashi, H. (2008). Ursolic Acid: an Anti- and Proinflammatory Triterpenoid. Mol. Nutr. Food Res. 52, 26-42. doi:10.1002/ mnfr.200700389

Israel, L. L. (2018). A Nanomedicine Approach to Manage Cancer - Imaging Pancreatic Cancer Using Targeted Iron Oxide Nanoparticles. EBioMedicine 30, 7-8. doi:10.1016/j.ebiom.2018.03.011

Jarvis, M., Krishnan, V., and Mitragotri, S. (2019). Nanocrystals: A Perspective on Translational Research and Clinical Studies. Bioeng. Transl. Med. 4, 5-16. doi:10.1002/btm2.10122

Jiang, W., Huang, R.-Z., Zhang, J., Guo, T., Zhang, M.-T., Huang, X.-C., et al. (2018). Discovery of Antitumor Ursolic Acid Long-Chain Diamine Derivatives as Potent Inhibitors of NF-Kb. Bioorg. Chem. 79, 265-276. doi:10.1016/ j.bioorg.2018.05.005

Jin, H., Pi, J., Yang, F., Jiang, J., Wang, X., Bai, H., et al. (2016a). Folate-Chitosan Nanoparticles Loaded with Ursolic Acid Confer Anti-breast Cancer Activities In Vitro and In Vivo. Sci. Rep. 6, 30782. doi:10.1038/srep30782

Jin, H., Pi, J., Yang, F., Wu, C., Cheng, X., Bai, H., et al. (2016b). Ursolic AcidLoaded Chitosan Nanoparticles Induce Potent Anti-angiogenesis in Tumor. Appl. Microbiol. Biotechnol. 100, 6643-6652. doi:10.1007/s00253-016-7360-8

Jinhua, W. (2019). Ursolic Acid: Pharmacokinetics Processin Vitroandin Vivo, a Mini Review. Arch. Pharm. Chem. Life Sci. 352, 1800222. doi:10.1002/ ardp. 201800222

Jinhua, W., Ying, Z., and Yuhua, L. (2020). PXR-ABC Drug transporters/CYPmediated Ursolic Acid Transport and Metabolism In Vitro and Vivo. Arch. Pharm. 353, 2000082. doi:10.1002/ardp.202000082

Kalani, K., Yadav, D. K., Khan, F., Srivastava, S. K., and Suri, N. (2012). Pharmacophore, QSAR, and ADME Based Semisynthesis and In Vitro Evaluation of Ursolic Acid Analogs for Anticancer Activity. J. Mol. Model. 18, 3389-3413. doi:10.1007/s00894-011-1327-6

Kalani, K., Yadav, D., Singh, A., Khan, F., Godbole, M. M., and Srivastava, S. K. (2014). QSAR Guided Semi-synthesis and In-Vitro Validation of Anticancer Activity in Ursolic Acid Derivatives. Ctmc 14, 1005-1013. doi:10.2174/ 1568026614666140324121606

Kalyane, D., Raval, N., Maheshwari, R., Tambe, V., Kalia, K., and Tekade, R. K. (2019). Employment of Enhanced Permeability and Retention Effect (EPR): Nanoparticle-Based Precision Tools for Targeting of Therapeutic and Diagnostic Agent in Cancer. Mater. Sci. Eng. C 98, 1252-1276. doi:10.1016/ j.msec.2019.01.066

Katz, L., and Baltz, R. H. (2016). Natural Product Discovery: Past, Present, and Future. J. Ind. Microbiol. Biotechnol. 43, 155-176. doi:10.1007/s10295-0151723-5

Khan, I., Bahuguna, A., Kumar, P., Bajpai, V. K., and Kang, S. C. (2018). In Vitro and In Vivo Antitumor Potential of Carvacrol Nanoemulsion against Human Lung Adenocarcinoma A549 Cells via Mitochondrial Mediated Apoptosis. Sci. Rep. 8, 144. doi:10.1038/s41598-017-18644-9

Khwaza, V., Oyedeji, O. O., and Aderibigbe, B. A. (2020). Ursolic Acid-Based Derivatives as Potential Anti-cancer Agents: An Update. Int. J. Mol. Sci. 21, 5920. doi:10.3390/ijms 21165920

Kim, K., Shin, E., Jung, J., Park, J., Kim, D., Shim, B., et al. (2018). Ursolic Acid Induces Apoptosis in Colorectal Cancer Cells Partially via Upregulation of MicroRNA-4500 and Inhibition of JAK2/STAT3 Phosphorylation. Int. J. Mol. Sci. 20, 114. doi:10.3390/ijms20010114

Lam, D. T., Le, V. T. T., Quan, P. M., Minh, P. T. H., Thuy, T. T. T., Anh, N. T. N., et al. (2019). Two New Terpenoids from the Leaves of Callicarpa Macrophylla. Nat. Prod. Res. 35, 1107-1114. doi:10.1080/14786419.2019.1639180

Lee, H. (2020). Molecular Simulations of PEGylated Biomolecules, Liposomes, and Nanoparticles for Drug Delivery Applications. Pharmaceutics 12, 533. doi:10.3390/pharmaceutics12060533
Lewinska, A., Adamczyk-Grochala, J., Kwasniewicz, E., Deregowska, A., and Wnuk, M. (2017a). Ursolic Acid-Mediated Changes in Glycolytic Pathway Promote Cytotoxic Autophagy and Apoptosis in Phenotypically Different Breast Cancer Cells. Apoptosis 22, 800-815. doi:10.1007/s10495-017-1353-7

Lewinska, A., Bednarz, D., Adamczyk-Grochala, J., and Wnuk, M. (2017b). Phytochemical-induced Nucleolar Stress Results in the Inhibition of Breast Cancer Cell Proliferation. Redox Biol. 12, 469-482. doi:10.1016/ j.redox.2017.03.014

Li, C., Wang, X., Song, H., Deng, S., Li, W., Li, J., et al. (2020). Current Multifunctional Albumin-Based Nanoplatforms for Cancer Multi-Mode Therapy. Asian J. Pharm. Sci. 15, 1-12. doi:10.1016/j.ajps.2018.12.006

Li, Q., Xiong, Y., Ji, C., and Yan, Z. (2019). The Application of Nanotechnology in the Codelivery of Active Constituents of Plants and Chemotherapeutics for Overcoming Physiological Barriers during Antitumor Treatment. Biomed. Res. Int. 2019, 1-16. doi:10.1155/2019/9083068

Li, T., Chen, X., Liu, Y., Fan, L., Lin, L., Xu, Y., et al. (2017). pH-Sensitive Mesoporous Silica Nanoparticles Anticancer Prodrugs for Sustained Release of Ursolic Acid and the Enhanced Anti-cancer Efficacy for Hepatocellular Carcinoma Cancer. Eur. J. Pharm. Sci. 96, 456-463. doi:10.1016/ j.ejps.2016.10.019

Li, W., Yan, R., Liu, Y., He, C., Zhang, X., Lu, Y., et al. (2019). Co-delivery of Bmil Small Interfering RNA with Ursolic Acid by Folate Receptor-Targeted Cationic Liposomes Enhances Anti-tumor Activity of Ursolic Acid In Vitro and In Vivo. Drug Deliv. 26, 794-802. doi:10.1080/10717544.2019.1645244

Li, W., Zhang, H., Nie, M., Tian, Y., Chen, X., Chen, C., et al. (2017). Ursolic Acid Derivative FZU-03,010 Inhibits STAT3 and Induces Cell Cycle Arrest and Apoptosis in Renal and Breast Cancer Cells. Acta Biochim. Biophys. Sin. 49, 367-373. doi:10.1093/abbs/gmx012

Li, W., Zhang, H., Nie, M., Wang, W., Liu, Z., Chen, C., et al. (2018). A Novel Synthetic Ursolic Acid Derivative Inhibits Growth and Induces Apoptosis in Breast Cancer Cell Lines. Oncol. Lett. 15, 2323-2329. doi:10.3892/ ol.2017.7578

Li, Z., Ma, D., He, Y., Guo, S., Liu, F., and Liu, X. (2020). Simultaneous Ultrasound and Heat Enhance Functional Properties of Glycosylated Lactoferrin. Molecules, 25, 5774. doi:10.3390/molecules25235774

Li, Z., Sun, J., Huang, Y., Liu, Y., Xu, J., Chen, Y., et al. (2018). A Nanomicellar Prodrug Carrier Based on Ibuprofen-Conjugated Polymer for Co-delivery of Doxorubicin. Front. Pharmacol. 9, 781. doi:10.3389/fphar.2018.00781

Liao, H., Gao, Y., Lian, C., Zhang, Y., Wang, B., Yang, Y., et al. (2019). Oral Absorption and Lymphatic Transport of Baicalein Following DrugPhospholipid Complex Incorporation in Self-Microemulsifying Drug Delivery Systems. Int. J. Nanomed. 14, 7291-7306. doi:10.2147/ ijn.S214883

Limami, Y., Pinon, A., Leger, D. Y., Pinault, E., Delage, C., Beneytout, J.-L., et al. (2012). The P2Y2/Src/p38/COX-2 Pathway Is Involved in the Resistance to Ursolic Acid-Induced Apoptosis in Colorectal and Prostate Cancer Cells. Biochimie 94, 1754-1763. doi:10.1016/j.biochi.2012.04.006

Lin, C.-C., Huang, C.-Y., Mong, M.-C., Chan, C.-Y., and Yin, M.-C. (2011). Antiangiogenic Potential of Three Triterpenic Acids in Human Liver Cancer Cells. J. Agric. Food Chem. 59, 755-762. doi:10.1021/jf103904b

Lin, J., Chen, Y., Wei, L., Hong, Z., Sferra, T. J., and Peng, J. (2013a). Ursolic Acid Inhibits Colorectal Cancer Angiogenesis through Suppression of Multiple Signaling Pathways. Int. J. Oncol. 43, 1666-1674. doi:10.3892/ijo.2013.2101

Lin, J., Chen, Y., Wei, L., Shen, A., Sferra, T. J., Hong, Z., et al. (2013b). Ursolic Acid Promotes Colorectal Cancer Cell Apoptosis and Inhibits Cell Proliferation via Modulation of Multiple Signaling Pathways. Int. J. Oncol. 43, 1235-1243. doi:10.3892/ijo.2013.2040

Liu, T., Ma, H., Shi, W., Duan, J., Wang, Y., Zhang, C., et al. (2017). Inhibition of STAT3 Signaling Pathway by Ursolic Acid Suppresses Growth of Hepatocellular Carcinoma. Int. J. Oncol. 51, 555-562. doi:10.3892/ijo.2017.4035

Liu, T., Mu, L.-Q., Dai, W., Wang, C.-b., Liu, X.-Y., and Xiang, D.-X. (2016). Preparation, Characterization, and Evaluation of Antitumor Effect of Brucea Javanica Oil Cationic Nanoemulsions. Int. J. Nanomed. 11, 2515-2529. doi:10.2147/ijn.S101918

Liu, Z., Ye, W., Zheng, J., Wang, Q., Ma, G., Liu, H., et al. (2020). Hierarchically Electrospraying a PLGA@chitosan Sphere-In-Sphere Composite Microsphere for Multi-Drug-Controlled Release. Regenerative Biomater. 7, 381-390. doi:10.1093/rb/rbaa009 
Lu, J., Hu, J., Liang, Y., and Cui, W. (2019). The Supramolecular Organogel Formed by Self-Assembly of Ursolic Acid Appended with Aromatic Rings. Materials 12, 614. doi:10.3390/ma12040614

Luo, J., Hu, Y.-L., and Wang, H. (2017). Ursolic Acid Inhibits Breast Cancer Growth by Inhibiting Proliferation, Inducing Autophagy and Apoptosis, and Suppressing Inflammatory Responses via the PI3K/AKT and NF-Kb Signaling Pathways In Vitro. Exp. Ther. Med. 14, 3623-3631. doi:10.3892/etm.2017.4965

Ma, Z., Fan, Y., Wu, Y., Kebebe, D., Zhang, B., Lu, P., et al. (2019). Traditional Chinese Medicine-Combination Therapies Utilizing Nanotechnology-Based Targeted Delivery Systems: a New Strategy for Antitumor Treatment. Int. J. Nanomed. 14, 2029-2053. doi:10.2147/ijn.S197889

Majidzadeh, H., Araj-Khodaei, M., Ghaffari, M., Torbati, M., Ezzati Nazhad Dolatabadi, J., and Hamblin, M. R. (2020). Nano-based Delivery Systems for Berberine: A Modern Anti-cancer Herbal Medicine. Colloids Surf. B: Biointerfaces 194, 111188. doi:10.1016/.j.colsurfb.2020.111188

Manayi, A., Nikan, M., Nobakht-Haghighi, N., and Abdollahi, M. (2019). Advances in the Anticancer Value of the Ursolic Acid through Nanodelivery. Curr. Med. Chem. 25, 4866-4875. doi:10.2174/0929867324666170713102918

Martinez, J. O., Molinaro, R., Hartman, K. A., Boada, C., Sukhovershin, R., De Rosa, E., et al. (2018). Biomimetic Nanoparticles with Enhanced Affinity towards Activated Endothelium as Versatile Tools for Theranostic Drug Delivery. Theranostics 8, 1131-1145. doi:10.7150/thno.22078

Masserini, M. (2013). Nanoparticles for Brain Drug Delivery. ISRN Biochem. 2013, 1-18. doi:10.1155/2013/238428

Mendes, V. I. S., Bartholomeusz, G. A., Ayres, M., Gandhi, V., and Salvador, J. A. R. (2016). Synthesis and Cytotoxic Activity of Novel A-Ring Cleaved Ursolic Acid Derivatives in Human Non-small Cell Lung Cancer Cells. Eur. J. Med. Chem. 123, 317-331. doi:10.1016/j.ejmech.2016.07.045

Meng, Y., Lin, Z.-M., Ge, N., Zhang, D.-L., Huang, J., and Kong, F. (2015). Ursolic Acid Induces Apoptosis of Prostate Cancer Cells via the PI3K/Akt/mTOR Pathway. Am. J. Chin. Med. 43, 1471-1486. doi:10.1142/s0192415x15500834

Miastkowska, M., and Śliwa, P. (2020). Influence of Terpene Type on the Release from an O/W Nanoemulsion: Experimental and Theoretical Studies. Molecules 25, 2747. doi:10.3390/molecules 25122747

Moradi Kashkooli, F., Soltani, M., and Souri, M. (2020). Controlled Anti-cancer Drug Release through Advanced Nano-Drug Delivery Systems: Static and Dynamic Targeting Strategies. J. Controlled Release 327, 316-349. doi:10.1016/j.jconrel.2020.08.012

Mu, D., Zhou, G., Li, J., Su, B., and Guo, H. (2018). Ursolic Acid Activates the Apoptosis of Prostate Cancer via ROCK/PTEN Mediated Mitochondrial Translocation of Cofilin-1. Oncol. Lett. 15, 3202-3206. doi:10.3892/ ol.2017.7689

Nakamura, H., Jun, F., Maeda, H., and Maeda, H. (2015). Development of NextGeneration Macromolecular Drugs Based on the EPR Effect: Challenges and Pitfalls. Expert Opin. Drug Deliv. 12, 53-64. doi:10.1517/17425247.2014.955011

Nakamura, Y., Mochida, A., Choyke, P. L., and Kobayashi, H. (2016). Nanodrug Delivery: Is the Enhanced Permeability and Retention Effect Sufficient for Curing Cancer?. Bioconjug. Chem. 27, 2225-2238. doi:10.1021/ acs.bioconjchem.6b00437

Naseema, A., Kovooru, L., Behera, A. K., Kumar, K. P. P., and Srivastava, P. (2021). A Critical Review of Synthesis Procedures, Applications and Future Potential of Nanoemulsions. Adv. Colloid Interf. Sci 287, 102318. doi:10.1016/ j.cis. 2020.102318

Ngo, T. N., Vo, C. T., Pham, N. K. T., Phan, N. M., Bui, T. D., Ngo, Q. L., et al. (2019). Markhacanasin C, Cycloartane Triterpenoid from the Leaves of Markhamia Stipulata Var. Canaense V.S. Dang. Nat. Product. Res. 33, 174-179. doi:10.1080/14786419.2018.1440227

Omoyeni, O. A., Hussein, A., Meyer, M., Green, I., and Iwuoha, E. (2015). Pleiocarpa Pycnantha Leaves and its Triterpenes Induce Apoptotic Cell Death in Caco-2 Cells In Vitro. BMC Complement. Altern. Med. 15, 224. doi:10.1186/s12906-015-0767-4

Patik, I., Kovacsics, D., Német, O., Gera, M., Várady, G., Stieger, B., et al. (2015). Functional Expression of the 11 Human Organic Anion Transporting Polypeptides in Insect Cells Reveals that Sodium Fluorescein Is a General OATP Substrate. Biochem. Pharmacol. 98, 649-658. doi:10.1016/ j.bcp.2015.09.015

Pi, J., Liu, Z., Wang, H., Gu, X., Wang, S., Zhang, B., et al. (2016). Ursolic Acid Nanocrystals for Dissolution Rate and Bioavailability Enhancement: Influence of Different Particle Size. Cdd 13, 1358-1366. doi:10.2174/ 1567201813666160307142757

Poudel, K., Gautam, M., Maharjan, S., Jeong, J.-H., Choi, H.-G., Khan, G. M., et al. (2020). Dual Stimuli-Responsive Ursolic Acid-Embedded Nanophytoliposome for Targeted Antitumor Therapy. Int. J. pharmaceutics 582, 119330. doi:10.1016/j.ijpharm.2020.119330

Prasad, S., Yadav, V. R., Sung, B., Reuter, S., Kannappan, R., Deorukhkar, A., et al. (2012). Ursolic Acid Inhibits Growth and Metastasis of Human Colorectal Cancer in an Orthotopic Nude Mouse Model by Targeting Multiple Cell Signaling Pathways: Chemosensitization with Capecitabine. Clin. Cancer Res. 18, 4942-4953. doi:10.1158/1078-0432.Ccr-11-2805

Qian, Z., Wang, X., Song, Z., Zhang, H., Zhou, S., Zhao, J., et al. (2015). A Phase I Trial to Evaluate the Multiple-Dose Safety and Antitumor Activity of Ursolic Acid Liposomes in Subjects with Advanced Solid Tumors. Biomed. Res. Int. 2015, 1-7. doi:10.1155/2015/809714

Qiang, Z., Ye, Z., Hauck, C., Murphy, P. A., Mccoy, J.-A., Widrlechner, M. P., et al. (2011). Permeability of Rosmarinic Acid in Prunella Vulgaris and Ursolic Acid in Salvia Officinalis Extracts across Caco-2 Cell Monolayers. J. Ethnopharmacol. 137, 1107-1112. doi:10.1016/j.jep.2011.07.037

Qin, C., Xin, X., Pei, X., Yin, L., and He, W. (2018). Amorphous Nanosuspensions Aggregated from Paclitaxel-Hemoglobulin Complexes with Enhanced Cytotoxicity. Pharmaceutics 10, 92. doi:10.3390/pharmaceutics10030092

Qin, X., and Wang, X. (2019). Role of Vitamin D Receptor in the Regulation of CYP3A Gene Expression. Acta Pharmaceutica Sinica. B 9, 1087-1098. doi:10.1016/j.apsb.2019.03.005

Qiu, L., Zhao, X., Zu, Y., Zhang, Y., Liu, Y., Wu, W., et al. (2019). Ursolic Acid Nanoparticles for Oral Delivery Prepared by Emulsion Solvent Evaporation Method: Characterization, In Vitro Evaluation of Radical Scavenging Activity and Bioavailability. Artif. Cell Nanomed., Biotechnol. 47, 609-620. doi:10.1080/ 21691401.2019.1573739

Rocha, T. G. R., Lopes, S. C. d. A., Cassali, G. D., Ferreira, Ê., Veloso, E. S., Leite, E. A., et al. (2016). Evaluation of Antitumor Activity of Long-Circulating and pHSensitive Liposomes Containing Ursolic Acid in Animal Models of Breast Tumor and Gliosarcoma. Integr. Cancer Ther. 15, 512-524. doi:10.1177/ 1534735416628273

Roth, M., Araya, J. J., Timmermann, B. N., and Hagenbuch, B. (2011). Isolation of Modulators of the Liver-specific Organic Anion-Transporting Polypeptides (OATPs) 1B1 and 1B3 from Rollinia Emarginata Schlecht (Annonaceae). J. Pharmacol. Exp. Ther. 339, 624-632. doi:10.1124/ jpet.111.184564

Ruan, J. S., Zhou, H., Yang, L., Wang, L., Jiang, Z. S., Sun, H., et al. (2019). Ursolic Acid Attenuates TGF-B1-Induced Epithelial-Mesenchymal Transition in NSCLC by Targeting Integrin $\alpha \mathrm{V} \beta 5 / \mathrm{MMPs}$ Signaling. Oncol. Res. 27, 593-600. doi:10.3727/096504017x15051723858706

Schmid, A. J., Dubbert, J., Rudov, A. A., Pedersen, J. S., Lindner, P., Karg, M., et al. (2016). Multi-Shell Hollow Nanogels with Responsive Shell Permeability. Sci. Rep. 6, 22736. doi:10.1038/srep22736

Schmidt, N., Schulze, J., Warwas, D. P., Ehlert, N., Lenarz, T., Warnecke, A., et al. (2018). Long-term Delivery of Brain-Derived Neurotrophic Factor (BDNF) from Nanoporous Silica Nanoparticles Improves the Survival of Spiral Ganglion Neurons In Vitro. PLoS One 13, e0194778. doi:10.1371/ journal.pone. 0194778

Shan, J., Xuan, Y., Zhang, Q., Zhu, C., Liu, Z., and Zhang, S. (2016). Ursolic Acid Synergistically Enhances the Therapeutic Effects of Oxaliplatin in Colorectal Cancer. Protein Cell. 7, 571-585. doi:10.1007/s13238-016-0295-0

Shao, J., Fang, Y., Zhao, R., Chen, F., Yang, M., Jiang, J., et al. (2020). Evolution from Small Molecule to Nano-Drug Delivery Systems: An Emerging Approach for Cancer Therapy of Ursolic Acid. Asian J. Pharm. Sci. 15, 685-700. doi:10.1016/j.ajps.2020.03.001

Siboro, S. A. P., Salma, S. A., Kim, H.-R., Jeong, Y. T., Gal, Y.-S., and Lim, K. T. (2020). Diselenide Core Cross-Linked Micelles of Poly(Ethylene Oxide)-BPoly(Glycidyl Methacrylate) Prepared through Alkyne-Azide Click Chemistry as a Near-Infrared Controlled Drug Delivery System. Materials 13, 2846. doi: $10.3390 / \mathrm{ma1} 13122846$

Silva, A. M., Alvarado, H. L., Abrego, G., Martins-Gomes, C., Garduño-Ramirez, M. L., García, M. L., et al. (2019). In Vitro Cytotoxicity of Oleanolic/Ursolic Acids-Loaded in PLGA Nanoparticles in Different Cell Lines. Pharmaceutics 11, 362. doi:10.3390/pharmaceutics11080362 
Son, H.-S., Kwon, H. Y., Sohn, E. J., Lee, J.-H., Woo, H.-J., Yun, M., et al. (2013). Activation of AMP-Activated Protein Kinase and Phosphorylation of Glycogen Synthase Kinase $3 \beta$ Mediate Ursolic Acid Induced Apoptosis in HepG2 Liver Cancer Cells. Phytother. Res. 27, 1714-1722. doi:10.1002/ptr.4925

Son, J., and Lee, S. Y. (2020). Therapeutic Potential of Ursonic Acid: Comparison with Ursolic Acid. Biomolecules 10, 1505. doi:10.3390/biom10111505

Song, J., Wang, Y., Song, Y., Chan, H., Bi, C., Yang, X., et al. (2014). Development and Characterisation of Ursolic Acid Nanocrystals without Stabiliser Having Improved Dissolution Rate and In Vitro Anticancer Activity. AAPS PharmSciTech 15, 11-19. doi:10.1208/s12249-013-0028-0

Souto, E. B., Dias-Ferreira, J., Oliveira, J., Sanchez-Lopez, E., Lopez-Machado, A., Espina, M., et al. (2019). Trends in Atopic Dermatitis-From Standard Pharmacotherapy to Novel Drug Delivery Systems. Ijms 20, 5659. doi:10.3390/ijms20225659

Su, C., Liu, Y., He, Y., and Gu, J. (2018). Analytical Methods for Investigating In Vivo Fate of Nanoliposomes: A Review. J. Pharm. Anal. 8, 219-225. doi:10.1016/j.jpha.2018.07.002

Sun, Q., He, M., Zhang, M., Zeng, S., Chen, L., Zhou, L., et al. (2020). Ursolic Acid: A Systematic Review of its Pharmacology, Toxicity and Rethink on its Pharmacokinetics Based on PK-PD Model. Fitoterapia 147, 104735. doi:10.1016/j.fitote.2020.104735

Sun, S., Guan, Q., Shang, E., Xiao, H., Yu, X., Shi, L., et al. (2020). Hyaluronic AcidCoated Nanostructured Lipid Carriers for Loading Multiple Traditional Chinese Medicine Components for Liver Cancer Treatment. Pak J. Pharm. Sci. 33, 109-119. doi:10.26559/mersinsbd.682854

Talukdar, M. I. A., Akram, M. K., Singh, T., Malik, M. A., Dar, O. A., and Hashmi, A. A. (2019). In-situ Modification of castor Oil with Divalent Metal Ions like Zn (II), Cu (II), Co (II) and Ba (II) and Their Comparative Antioxidant Study by In-Vitro Methods. Food Chem. 284, 213-218. doi:10.1016/ j.foodchem.2019.01.033

Tanka-Salamon, A., Bóta, A., Wacha, A., Mihály, J., Lovas, M., and Kolev, K. (2017). Structure and Function of Trypsin-Loaded Fibrinolytic Liposomes. Biomed. Res. Int. 2017, 1-10. doi:10.1155/2017/5130495

Telang, N. (2018). Anti-proliferative and Proapoptotic Effects of Rosemary and Constituent Terpenoids in a Model for the HER-2-enriched Molecular Subtype of Clinical Breast Cancer. Oncol. Lett. 16, 5489-5497. doi:10.3892/ol.2018.9238

Teymouri Rad, R., Mortazavi, S. A., Vatanara, A., and Dadashzadeh, S. (2017). Enhanced Dissolution Rate of Tadalafil Nanoparticles Prepared by Sonoprecipitation Technique: Optimization and Physicochemical Investigation. Iran J. Pharm. Res. 16, 1335-1348.

Tjandrawinata, R. R., Setiawati, A., Nofiarny, D., Susanto, L. W., and Setiawati, E. (2018). Pharmacokinetic Equivalence Study of Nonsteroidal Antiinflammatory Drug Etoricoxib. Clin. Pharmacol. 10, 43-51. doi:10.2147/ cpaa.S161024

Torres-Rosas, R., Torres-Gómez, N., Moreno-Rodríguez, A., García-Contreras, R., and Argueta-Figueroa, L. (2020). Anti-Inflammatory and Antibacterial Activity of the Chitosan/Chlorhexidine Gel Commercial Preparation for Postexodontia Treatment: An In Vitro Study. Eur. J. Dent 14, 397-403. doi:10.1055/s-00401714453

Vong, L. B., and Nagasaki, Y. (2020). Nitric Oxide Nano-Delivery Systems for Cancer Therapeutics: Advances and Challenges. Antioxidants 9, 791. doi:10.3390/antiox9090791

Vora, L. K., Vavia, P. R., Larrañeta, E., Bell, S. E. J., and Donnelly, R. F. (2018). Novel Nanosuspension-Based Dissolving Microneedle Arrays for Transdermal Delivery of a Hydrophobic Drug. J. Interdiscip. Nanomed. 3, 89-101. doi:10.1002/jin2.41

Wadajkar, A. S., Dancy, J. G., Carney, C. P., Hampton, B. S., Ames, H. M., Winkles, J. A., et al. (2019). Leveraging Surface Plasmon Resonance to Dissect the Interfacial Properties of Nanoparticles: Implications for Tissue Binding and Tumor Penetration. Nanomedicine: Nanotechnology, Biol. Med. 20, 102024. doi:10.1016/j.nano.2019.102024

Wan, S.-Z., Liu, C., Huang, C.-K., Luo, F.-Y., and Zhu, X. (2019). Ursolic Acid Improves Intestinal Damage and Bacterial Dysbiosis in Liver Fibrosis Mice. Front. Pharmacol. 10, 1321. doi:10.3389/fphar.2019.01321

Wang, J., Lv, F.-M., Wang, D.-L., Du, J.-L., Guo, H.-Y., Chen, H.-N., et al. (2020a). Synergistic Antitumor Effects on Drug-Resistant Breast Cancer of Paclitaxel/ Lapatinib Composite Nanocrystals. Molecules 25, 604. doi:10.3390/ molecules 25030604
Wang, J., Zhao, H., Zhi, K., and Yang, X. (2020b). Exploration of the Natural Active Small-Molecule Drug-Loading Process and Highly Efficient Synergistic Antitumor Efficacy. ACS Appl. Mater. Inter. 12, 6827-6839. doi:10.1021/ acsami.9b18443

Wang, M., Yu, H., Wu, R., Chen, Z. Y., Hu, Q., Zhang, Y. F., et al. (2020). Autophagy Inhibition Enhances the Inhibitory Effects of Ursolic Acid on Lung Cancer Cells. Int. J. Mol. Med. 46, 1816-1826. doi:10.3892/ijmm.2020.4714

Wang, M., Zhao, T., Liu, Y., Wang, Q., Xing, S., Li, L., et al. (2017). Ursolic Acid Liposomes with Chitosan Modification: Promising Antitumor Drug Delivery and Efficacy. Mater. Sci. Eng. C 71, 1231-1240. doi:10.1016/j.msec.2016.11.014

Wang, S., Meng, X., and Dong, Y. (2017). Ursolic Acid Nanoparticles Inhibit Cervical Cancer Growth In Vitro and In Vivo via Apoptosis Induction. Int. J. Oncol. 50, 1330-1340. doi:10.3892/ijo.2017.3890

Wang, X.-H., Zhou, S.-Y., Qian, Z.-Z., Zhang, H.-L., Qiu, L.-H., Song, Z., et al. (2013). Evaluation of Toxicity and Single-Dose Pharmacokinetics of Intravenous Ursolic Acid Liposomes in Healthy Adult Volunteers and Patients with Advanced Solid Tumors. Expert Opin. Drug Metab. Toxicol. 9, 117-125. doi:10.1517/17425255.2013.738667

Wang, X., Wang, T., Yi, F., Duan, C., Wanwg, Q., He, N., et al. (2019). Ursolic Acid Inhibits Tumor Growth via Epithelial-To-Mesenchymal Transition in Colorectal Cancer Cells. Biol. Pharm. Bull. 42, 685-691. doi:10.1248/ bpb.b18-00613

Wang, Y., Song, J., Chow, S. F., Chow, A. H. L., and Zheng, Y. (2015). Particle Size Tailoring of Ursolic Acid Nanosuspensions for Improved Anticancer Activity by Controlled Antisolvent Precipitation. Int. J. Pharm. 494, 479-489. doi:10.1016/j.ijpharm.2015.08.052

Wang, Z., Wu, J., Shi, X., Song, F., Gao, W., and Liu, S. (2020d). Stereocomplexation of Poly(Lactic Acid) and Chemical Crosslinking of Ethylene Glycol Dimethacrylate (EGDMA) Double-Crosslinked Temperature/pH Dual Responsive Hydrogels. Polymers 12, 2204. doi:10.3390/polym 12102204

Wen, L., Guo, R., You, L., Abbasi, A. M., Li, T., Fu, X., et al. (2017). Major Triterpenoids in Chinese Hawthorn "Crataegus Pinnatifida" and Their Effects on Cell Proliferation and Apoptosis Induction in MDA-MB-231 Cancer Cells. Food Chem. Toxicol. 100, 149-160. doi:10.1016/j.fct.2016.12.032

Wu, J., Zhao, S., Tang, Q., Zheng, F., Chen, Y., Yang, L., et al. (2015). Activation of SAPK/JNK Mediated the Inhibition and Reciprocal Interaction of DNA Methyltransferase 1 and EZH2 by Ursolic Acid in Human Lung Cancer Cells. J. Exp. Clin. Cancer Res. 34, 99. doi:10.1186/s13046-015-0215-9

Xavier, C. P. R., Lima, C. F., Pedro, D. F. N., Wilson, J. M., Kristiansen, K., and Pereira-Wilson, C. (2013). Ursolic Acid Induces Cell Death and Modulates Autophagy through JNK Pathway in Apoptosis-Resistant Colorectal Cancer Cells. J. Nutr. Biochem. 24, 706-712. doi:10.1016/j.jnutbio.2012.04.004

Xia, Y. J., Xia, H., Chen, L., Ying, Q. S., Yu, X., Li, L. H., et al. (2018). Efficient Delivery of Recombinant Human Bone Morphogenetic Protein (rhBMP-2) with Dextran Sulfatechitosan Microspheres. Exp. Ther. Med. 15, 3265-3272. doi:10.3892/etm.2018.5849

Xia, Y., Wei, G., Si, D., and Liu, C. (2011). Quantitation of Ursolic Acid in Human Plasma by Ultra Performance Liquid Chromatography Tandem Mass Spectrometry and its Pharmacokinetic Study. J. Chromatogr. B 879, 219-224. doi:10.1016/j.jchromb.2010.11.037

Yan, F., Duan, W., Li, Y., Wu, H., Zhou, Y., Pan, M., et al. (2016). NIR-LaserControlled Drug Release from DOX/IR-780-Loaded Temperature-SensitiveLiposomes for Chemo-Photothermal Synergistic Tumor Therapy. Theranostics 6, 2337-2351. doi:10.7150/thno.14937

Yang, G., Yang, T., Zhang, W., Lu, M., Ma, X., and Xiang, G. (2014). In Vitro and In Vivo Antitumor Effects of Folate-Targeted Ursolic Acid Stealth Liposome. J. Agric. Food Chem. 62, 2207-2215. doi:10.1021/jf405675g

Yang, L., Sun, Z., Zu, Y., Zhao, C., Sun, X., Zhang, Z., et al. (2012). Physicochemical Properties and Oral Bioavailability of Ursolic Acid Nanoparticles Using Supercritical Anti-solvent (SAS) Process. Food Chem. 132, 319-325. doi:10.1016/j.foodchem.2011.10.083

Yang, Q., Zhao, C., Zhao, J., and Ye, Y. (2017). Photoresponsive Nanocapsulation of Cobra Neurotoxin and Enhancement of its central Analgesic Effects under Red Light. Int. J. Nanomed. 12, 3463-3470. doi:10.2147/ijn.S132510

Yi, Y.-S. (2016). Folate Receptor-Targeted Diagnostics and Therapeutics for Inflammatory Diseases. Immune Netw. 16, 337-343. doi:10.4110/ in.2016.16.6.337 
Yie, Y., Zhao, S., Tang, Q., Zheng, F., Wu, J., Yang, L., et al. (2015). Ursolic Acid Inhibited Growth of Hepatocellular Carcinoma HepG2 Cells through AMPKaMediated Reduction of DNA Methyltransferase 1. Mol. Cel Biochem 402, 63-74. doi:10.1007/s11010-014-2314-x

Yin, M.-C., Lin, M.-C., Mong, M.-C., and Lin, C.-Y. (2012). Bioavailability, Distribution, and Antioxidative Effects of Selected Triterpenes in Mice. J. Agric. Food Chem. 60, 7697-7701. doi:10.1021/jf302529x

Yousuf, M., Shamsi, A., Khan, P., Shahbaaz, M., Alajmi, M. F., Hussain, A., et al. (2020). Ellagic Acid Controls Cell Proliferation and Induces Apoptosis in Breast Cancer Cells via Inhibition of Cyclin-dependent Kinase 6. Ijms 21, 3526. doi:10.3390/ijms21103526

Yu, D., Kan, Z., Shan, F., Zang, J., and Zhou, J. (2020). Triple Strategies to Improve Oral Bioavailability by Fabricating Coamorphous Forms of Ursolic Acid with Piperine: Enhancing Water-Solubility, Permeability, and Inhibiting Cytochrome P450 Isozymes. Mol. Pharmaceutics 17, 4443-4462. doi:10.1021/acs.molpharmaceut.0c00443

Yu, M., Liu, T., Chen, Y., Li, Y., and Li, W. (2018). Combination Therapy with Protein Kinase Inhibitor H89 and Tetrandrine Elicits Enhanced Synergistic Antitumor Efficacy. J. Exp. Clin. Cancer Res. 37, 114. doi:10.1186/s13046-0180779-2

Yu, Y. X., Gu, Z. L., Yin, J. L., Chou, W. H., Kwok, C. Y., Qin, Z. H., et al. (2010). Ursolic Acid Induces Human Hepatoma Cell Line SMMC-7721 Apoptosis via P53-dependent Pathway. Chin. Med. J. (Engl) 123, 1915-1923.

Yuba, E., Osaki, T., Ono, M., Park, S., Harada, A., Yamashita, M., et al. (2018). Bleomycin-Loaded $\mathrm{pH}$-Sensitive Polymer-Lipid-Incorporated Liposomes for Cancer Chemotherapy. Polymers 10, 74. doi:10.3390/polym10010074

Zeng, C., Yu, F., Yang, Y., Cheng, X., Liu, Y., Zhang, H., et al. (2016). Preparation and Evaluation of Oxaliplatin Thermosensitive Liposomes with Rapid Release and High Stability. PLoS One 11, e0158517. doi:10.1371/ journal.pone.0158517

Zhai, Y., Zhou, X., Jia, L., Ma, C., Song, R., Deng, Y., et al. (2017). Acetal-Linked Paclitaxel Polymeric Prodrug Based on Functionalized mPEG-PCL Diblock Polymer for pH-Triggered Drug Delivery. Polymers 9, 698. doi:10.3390/ polym 9120698

Zhang, G., Zhang, Z., and Yang, J. (2017). DNA Tetrahedron Delivery Enhances Doxorubicin-Induced Apoptosis of HT-29 Colon Cancer Cells. Nanoscale Res. Lett. 12, 495. doi:10.1186/s11671-017-2272-9

Zhang, H., Zheng, D., Ding, J., Xu, H., Li, X., and Sun, W. (2015). Efficient Delivery of Ursolic Acid by poly(N-Vinylpyrrolidone)-Block-Poly ( $\varepsilon$-Caprolactone) Nanoparticles for Inhibiting the Growth of Hepatocellular Carcinoma In Vitro and In Vivo. Int. J. Nanomed. 10, 1909-1920. doi:10.2147/ijn.S77125

Zhang, L., Cai, Q. Y., Liu, J., Peng, J., Chen, Y. Q., Sferra, T., et al. (2019). Ursolic Acid Suppresses the Invasive Potential of Colorectal Cancer Cells by Regulating the TGF- $\beta 1 / Z E B 1 / m i R-200 c$ Signaling Pathway. Oncol. Lett. 18, 3274-3282. doi:10.3892/ol.2019.10604

Zhang, W., Dong, D., Li, P., Wang, D., Mu, H., Niu, H., et al. (2016). Novel pHSensitive Polysialic Acid Based Polymeric Micelles for Triggered Intracellular Release of Hydrophobic Drug. Carbohydr. Polym. 139, 75-81. doi:10.1016/ j.carbpol.2015.12.041

Zhang, X., Li, T., Gong, E. S., and Liu, R. H. (2020a). Antiproliferative Activity of Ursolic Acid in MDA-MB-231 Human Breast Cancer Cells through Nrf2
Pathway Regulation. J. Agric. Food Chem. 68, 7404-7415. doi:10.1021/ acs.jafc.0c03202

Zhang, X., Zhang, T., Ma, X., Wang, Y., Lu, Y., Jia, D., et al. (2020b). The Design and Synthesis of Dextran-Doxorubicin Prodrug-Based $\mathrm{pH}$-Sensitive Drug Delivery System for Improving Chemotherapy Efficacy. Asian J. Pharm. Sci. 15, 605-616. doi:10.1016/j.ajps.2019.10.001

Zhang, Y., Liu, B.-L., Wang, L.-J., Deng, Y.-H., Zhou, S.-Y., and Feng, J.-W. (2019). Preparation, Structure and Properties of Acid Aqueous Solution Plasticized Thermoplastic Chitosan. Polymers 11, 818. doi:10.3390/polym11050818

Zhao, R., Li, T., Zheng, G., Jiang, K., Fan, L., and Shao, J. (2017). Simultaneous Inhibition of Growth and Metastasis of Hepatocellular Carcinoma by Codelivery of Ursolic Acid and Sorafenib Using Lactobionic Acid Modified and pH-Sensitive Chitosan-Conjugated Mesoporous Silica Nanocomplex. Biomaterials 143, 1-16. doi:10.1016/j.biomaterials.2017.07.030

Zhao, R., Zheng, G., Fan, L., Shen, Z., Jiang, K., Guo, Y., et al. (2018). Carrier-free Nanodrug by Co-assembly of Chemotherapeutic Agent and Photosensitizer for Cancer Imaging and Chemo-Photo Combination Therapy. Acta Biomater. 70, 197-210. doi:10.1016/j.actbio.2018.01.028

Zhao, T., Liu, Y., Gao, Z., Gao, D., Li, N., Bian, Y., et al. (2015). Self-assembly and Cytotoxicity Study of PEG-Modified Ursolic Acid Liposomes. Mater. Sci. Eng. C 53, 196-203. doi:10.1016/j.msec.2015.04.022

Zheng, G., Shen, Y., Zhao, R., Chen, F., Zhang, Y., Xu, A., et al. (2017). DualTargeting Multifuntional Mesoporous Silica Nanocarrier for Codelivery of siRNA and Ursolic Acid to Folate Receptor Overexpressing Cancer Cells. J. Agric. Food Chem. 65, 6904-6911. doi:10.1021/acs.jafc.7b03047

Zheng, J., Wang, S. S., Shen, K. P., Huang, X. W., Li, M., Chen, L., et al. (2020). Ursolic Acid Potentiated Oxaliplatin to Induce Apoptosis in Colorectal Cancer RKO Cells. Pharmazie 75, 246-249. doi:10.1691/ph.2020.0417

Zhou, M., Yi, Y., Liu, L., Lin, Y., Li, J., Ruan, J., et al. (2019). Polymeric Micelles Loading with Ursolic Acid Enhancing Anti-tumor Effect on Hepatocellular Carcinoma. J. Cancer 10, 5820-5831. doi:10.7150/jca.30865

Zhou, Q., Dong, C., Fan, W., Jiang, H., Xiang, J., Qiu, N., et al. (2020). Tumor Extravasation and Infiltration as Barriers of Nanomedicine for High Efficacy: The Current Status and Transcytosis Strategy. Biomaterials 240, 119902. doi:10.1016/j.biomaterials.2020.119902

Zhu, Z., Qian, Z., Yan, Z., Zhao, C., Wang, H., and Ying, G. (2013). A Phase I Pharmacokinetic Study of Ursolic Acid Nanoliposomes in Healthy Volunteers and Patients with Advanced Solid Tumors. Int. J. Nanomed. 8, 129-136. doi:10.2147/ijn.S38271

Conflict of Interest: The authors declare that the research was conducted in the absence of any commercial or financial relationships that could be construed as a potential conflict of interest.

Copyright (c) 2021 Wang, Yin, Liu, Tang, Sun and Zhuang. This is an open-access article distributed under the terms of the Creative Commons Attribution License (CC $B Y)$. The use, distribution or reproduction in other forums is permitted, provided the original author(s) and the copyright owner(s) are credited and that the original publication in this journal is cited, in accordance with accepted academic practice. No use, distribution or reproduction is permitted which does not comply with these terms. 